\title{
¿De aldea fortificada a Caput Civitatis? Tradición y ruptura en una Comunidad Castreña del siglo I D.C.: El Poblado de Chao Samartín (Grandas de Salime, Asturias)'
}

\author{
ANGEL VILLA VALDÉS \\ Consejería de Cultura y Turismo del Principado de Asturias. \\ Plan Arqueológico del Navia- Eo
}

\section{Resumen}

El Chao Samartín es un paraje inmediato al pueblo de Castro, en la localidad asturiana de Grandas de Salime, donde las evidencias de asentamientos estables fortificados se remontan a fines de la Edad del Bronce (tránsito siglos IXVIII a.C.). La ocupación del lugar se prolongó durante la Edad del Hierro hasta bien consumada la implantación romana cuando, durante la segunda mitad del siglo II d.C., un violento seísmo asoló el poblado y precipitó su definitivo abandono.

Bajo dominio romano el castro adquiere, en un ambiente militarizado que se prolongará hasta fines del siglo I d.C, la condición de cabecera territorial, tal vez en calidad de caput civitatis. Se suceden en este tipo cambios sustanciales en las fortificaciones y en la trama edificada castreña hasta su consolidación como asentamiento abierto, residencia de grupos sociales preeminentes.

Sobre sus ruinas, ya en tiempos altomedievales, se instaló una necrópolis vigente en tiempos de la monarquía asturiana.

PALABRAS CLAVE: Castro, ejército, domus, minería aurífera, terremoto.

\section{Abstract}

The Chao Samartin site is located adjacent to the small village of Castro, in the Grandas de Salime Township (Asturias, northern Spain). The site displays evidence of fortified settlements from the Late Bronze Age, in the transition between the $9^{\text {th }}$ and $10^{\text {th }}$ Centuries b.C. Site occupation persisted during the Iron Age, until Roman control was well established. At that time (second half of the $2^{\text {nd }}$ Century a.D.), a violent earthquake destroyed the settlement, triggering its sudden abandonment.

The archaeological excavations began in 1990, from this moment on research went on without interruption, as a part of the Navia-Eo Archaeological Director Plan, under guidance and sponsorship of the Ministry of Culture and Tourism of the Principality of Asturias.

Roman presence is noticed from the first decades of the 1st century A.D. linked to the arrival of military forces to the settlement. The control and beginning of exploitation of the new conquered territories demanded the participation of the Roman army, which besides being skilful in battles, had the technical ability to direct the massive benefit of the gold mines, to construct the road links and to guarantee the safety of the extracted metal.

After the military victory, the organization of the conquered territories demanded the consolidation of regional power centres - Chao Samartín was one of them -which had peripheral control and militarized stations, as Monte Castrelo de Pelou. With the influence of the army, the centenary hillfort will experience its conversion into a relevant administrative centre, in which troops will act as effective agents for the introduction of the new culture.

KEY WORDS: Hillfort, roman army, roman house, roman gold mining, earthquake.

1 Este trabajo se ha realizado en el marco del Proyecto Nacional I+D "Formación y disolución de civitates en el NW peninsular. Estructuras de poblamiento y territorio"
(HAR-06018-CO3/HIST) dirigido por C. Fernández Ochoa (Universidad Autónoma de Madrid). 
Las ruinas del Chao Samartín se localizan en Castro, población que dista unos $6 \mathrm{Km}$ de Grandas de Salime, capital del concejo. Con una altitud máxima de $675 \mathrm{~m}$, el yacimiento se extiende sobre un promontorio cuyo sustratro geológico está constituido por cuarcitas blancas y materiales basales de la formación Agüeira originados durante el Ordovícico Medio y Superior (Marcos \& Ruiz, 1978: 12). La estratificación presenta una orientación N-S y las capas se encuentran en una posición subvertical que otorgan al paraje la singularidad topográfica que justificó su elección como asentamiento estable: hacia el Oeste, uno de los niveles de cuarcita de base determina una barrera casi vertical sobre el valle del río Cabalos mientras que, por el Este, la existencia de un nivel estratigráfico de menor competencia favoreció la formación de una depresión natural que proporciona al poblado un cierto dominio sobre el flanco oriental. Sendas vaguadas, con pronunciado desnivel hacia poniente, lo limitan al Norte y al Sur.

La existencia de antiguas fortificaciones en el lugar fue recogida a fines del siglo XVIIII por el corresponsal de Martínez Marina y posterior- mente, a comienzos del XX, por MéndezValledor para la obra Asturias de Bellmunt y Canella. En 1967 José Manuel González, tras proceder a su reconocimiento, lo incorpora al catálogo de castros asturianos (1976: 111). Las excavaciones arqueológicas dieron comienzo en 1990 como consecuencia de la revisión de los materiales procedentes del castro custodiados por José María Naveiras en el Museo Etnográfico de Grandas de Salime. Desde entonces las campañas de investigación se suceden con regularidad.

El horizonte de ocupación más antiguo se remonta a la Edad del Bronce cuando, en torno al año 800 a.C. se estableció un primer recinto fortificado (Villa \& Cabo, 2003). Éste se extendía, principalmente, sobre la explanada superior del yacimiento - una estrecha franja de apenas 30 metros de anchura y unos 80 de longitud- que protegían un foso, una muralla y una empalizada (Fig. 02). A su abrigo se construyó un gran edificio de planta rectangular y esquinas redondeadas que ha proporcionado cerámicas y objetos metálicos muy interesantes que junto a la ausencia de menaje y mobiliario doméstico sugieren

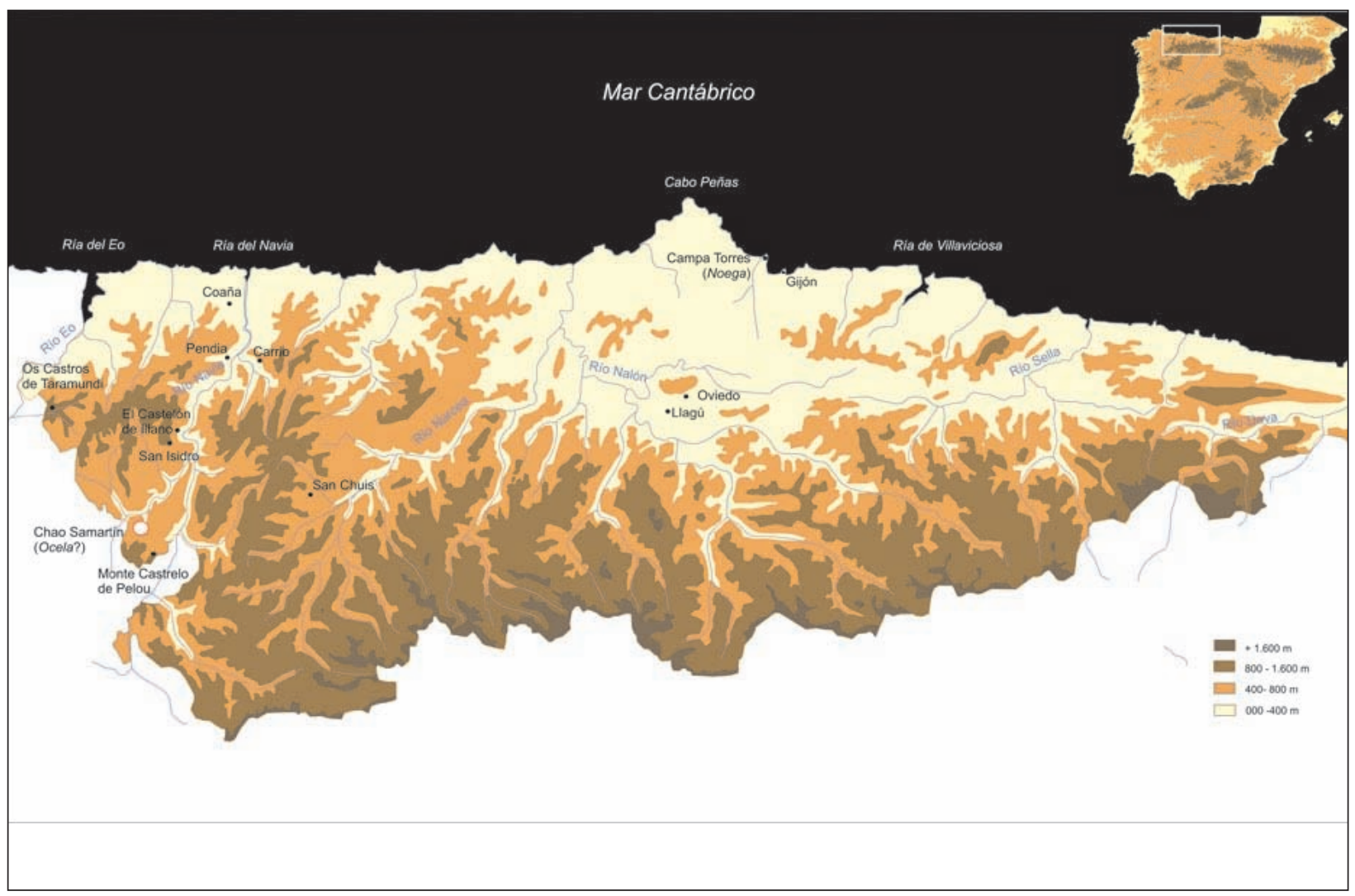

Figura 1: Localización del Chao Samartín y otros lugares mencionados en el texto. 


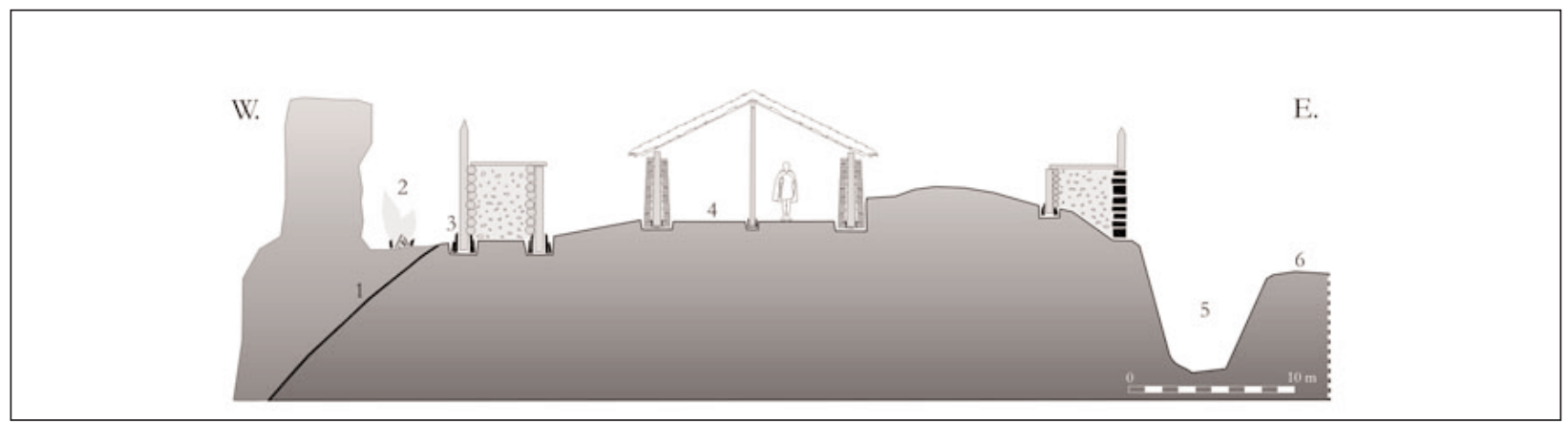

Figura 2: Sección ideal del recinto ceremonial instalado sobre la acrópolis del Chao Samartín hacia el año 800 a.C.

su utilización como espacio ceremonial ${ }^{2}$. El conjunto, fortificaciones y cabaña fueron destruidos por un incendio durante el siglo VII a.C..

Durante la Edad del Hierro el asentamiento se extendía por todo el promontorio defendido entonces con nuevas fortificaciones que habrían de mantenerse en uso -aunque con severas modificaciones en el trazado y la estructura- hasta la conquista romana. Se amortizaron así sucesivas líneas de fosos sobre los que, finalmente, se consolidó una muralla varias veces vencida y renovada (Fig. 03). Las reformas más importantes se producen entre el siglo IV y II a.C., cuando la vetusta fortificación, de estructura continua, adopta una compartimentación modular semejante a las que defendieron otros castros prerromanos del centro y occidente de Asturias (Villa, 2007). Ajustado a este cinturón defensivo se extendía un caserío en el que predominaban las construcciones de planta rectangular, con esquina de naipe, sobre las circulares y el aparejo de pizarra sobre el de cuarcitas,

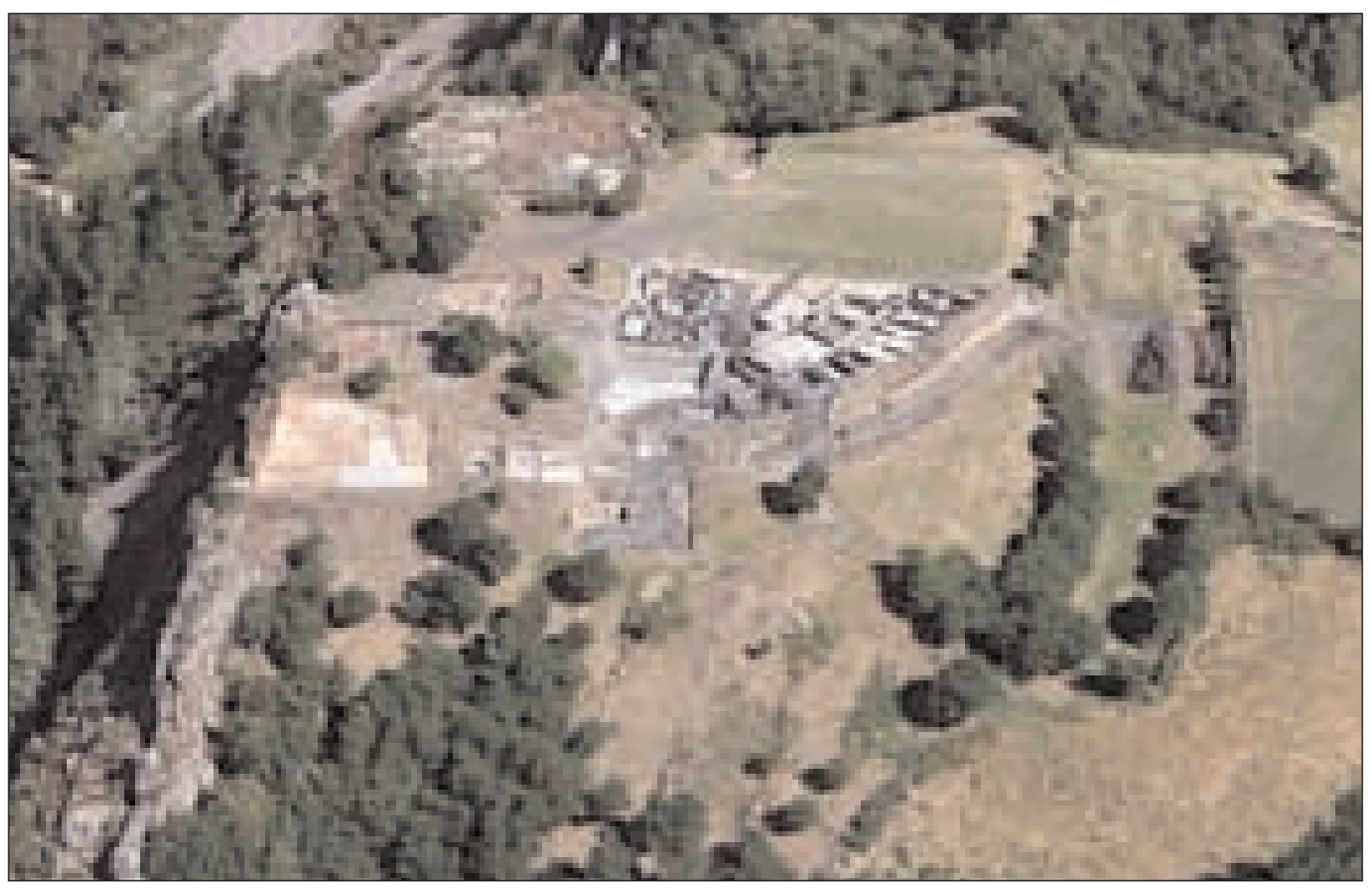

Figura 3: Vista aérea del Chao Samartín (octubre, 2003). En la imagen se advierten los principales elementos defensivos (fosos y muralla) así como el acceso meridional a la Acrópolis.

2 Una descripción pormenorizada de los objetos recuperados así como del contexto general de los hallazgos pueden consultarse para el conjunto de la colección en el catálogo de la exposición permanente del Museo Castro de Chao Samartín (Villa et alii., 2009). 
cuyo uso se restringe a las hiladas de nivelación y cimientos Todas ofrecen, de acuerdo con los parámetros de la arquitectura castreña clásica, planta sencilla e individualizada sin medianerías ni compartimentación del espacio interno. Al igual que en Coaña, Mohías o Pendia, también aparece una gran casa de asamblea, cabaña de planta oblonga y dimensiones notablemente superiores al resto. Inmediato se elevaba un edificio termal, pequeña construcción de planta rectangular y cabecera absidiada, que se destinaba a la toma de baños de vapor. Este tipo de sauna castreña, características del N.O. peninsular, eran consideradas hasta el descubrimiento de la del Chao Samartín meras adaptaciones rústicas del modelo termal clásico. Sin embargo, las investigaciones en curso en éste y otros castros del valle del Navia han revelado evidencias que permiten proponer para el grupo asturiano su implantación a partir de fines del siglo V o comienzos del siglo IV a.C. (Villa, 2007 b).

Entre otras actividades artesanales, destaca por su significación la metalurgia con metales preciosos -oro, plata y cobre- atestiguada por el descubrimiento de importantes acopios de tortas y cerámicas de fundición con salpicaduras metálicas, moldes, crisoles y diversas joyas (Villa, 2004). Cerámicas de almacenamiento y cocina, junto con algunas armas -entre las que se cuenta un puñal de antenas- completan el ajuar más destacable. La figura de dos caballos grabados sobre una pizarra constituye otro de los documentos epigráficos excepcionales durante estos siglos anteriores a la conquista.

El contacto con Roma se manifiesta con rotundidad durante la primera mitad del siglo I d.C., tiempo en el que se construye una magnífica domus dentro del recinto amurallado. El edificio, aún en proceso de excavación, muestra en la actualidad una planta próxima a los $500 \mathrm{~m}^{2}$, superficie que se distribuye, salvados los cuerpos de guardia, patio y fauces en una docena de estancias organizadas en torno a un atrio columnado de estilo toscano. Entre ellas pueden reconocerse el triclinium, varios cubicula, el tablinum y la cocina, a través de la cual se accede al cuerpo oriental del edificio donde se suceden varias estancias calefactadas mediante hipocaustum y * concamecationes con tubuli laterici (Madariaga et alli, 2001) tubu$l i$ parietales. Por el momento no cabe descartar el uso termal de esta parte del edificio tras la aparición de la base de una pequeña piscina o estanque y el programa ornamental desplegado sobre sus paredes. Al menos dos escaleras daban acceso a la planta superior sobre cuyas paredes de desplegó un amplio repertorio de motivos pictóricos (Gago, 2008-2009) (fig. 04/05/06/07).

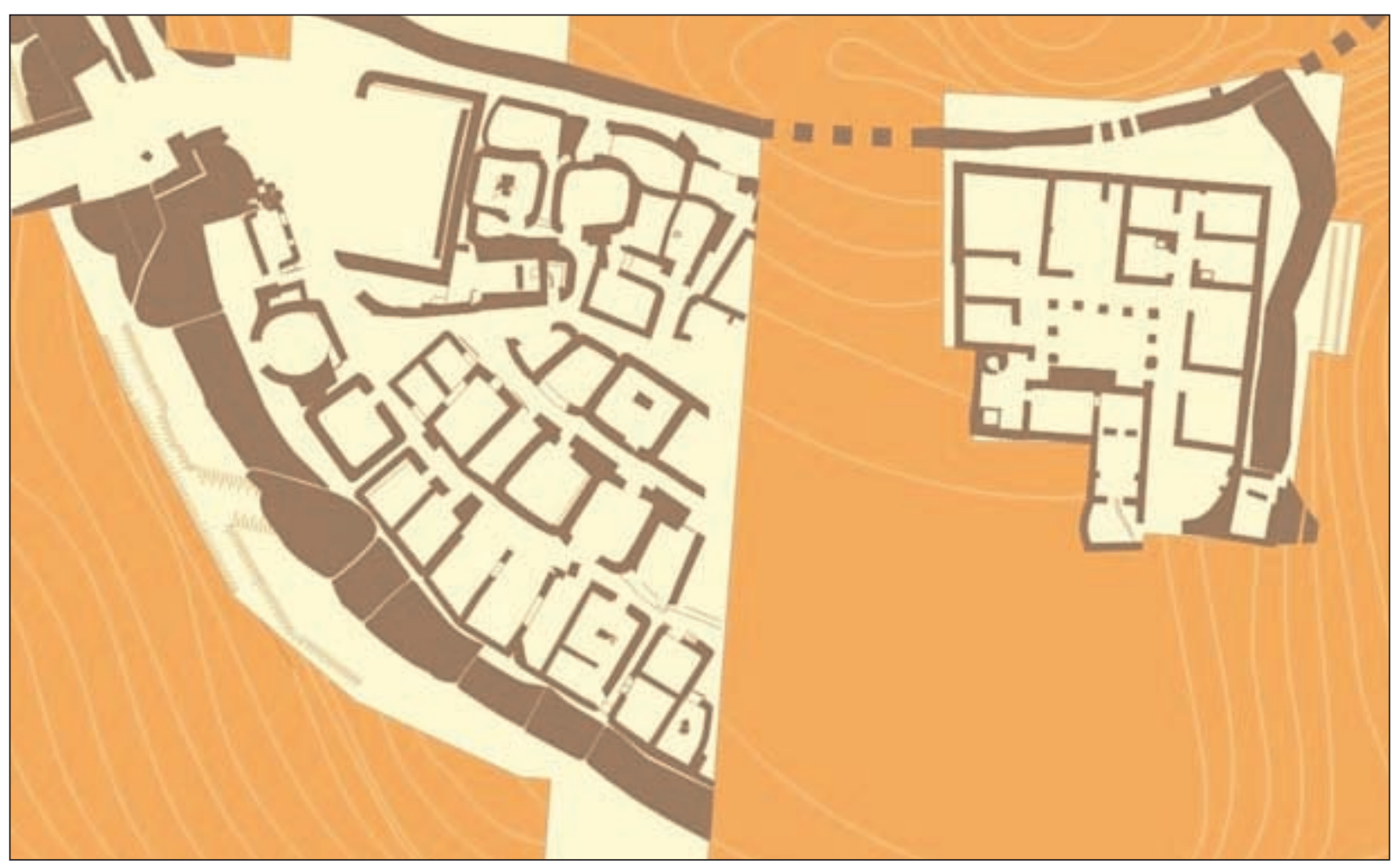

Figura 4: La trama edificada del poblado durante el siglo I d.C. muestra la integración en el tejido urbano prerromano de nuevas construcción entre las que destaca la domus instalada en el área septentrional del recinto. 


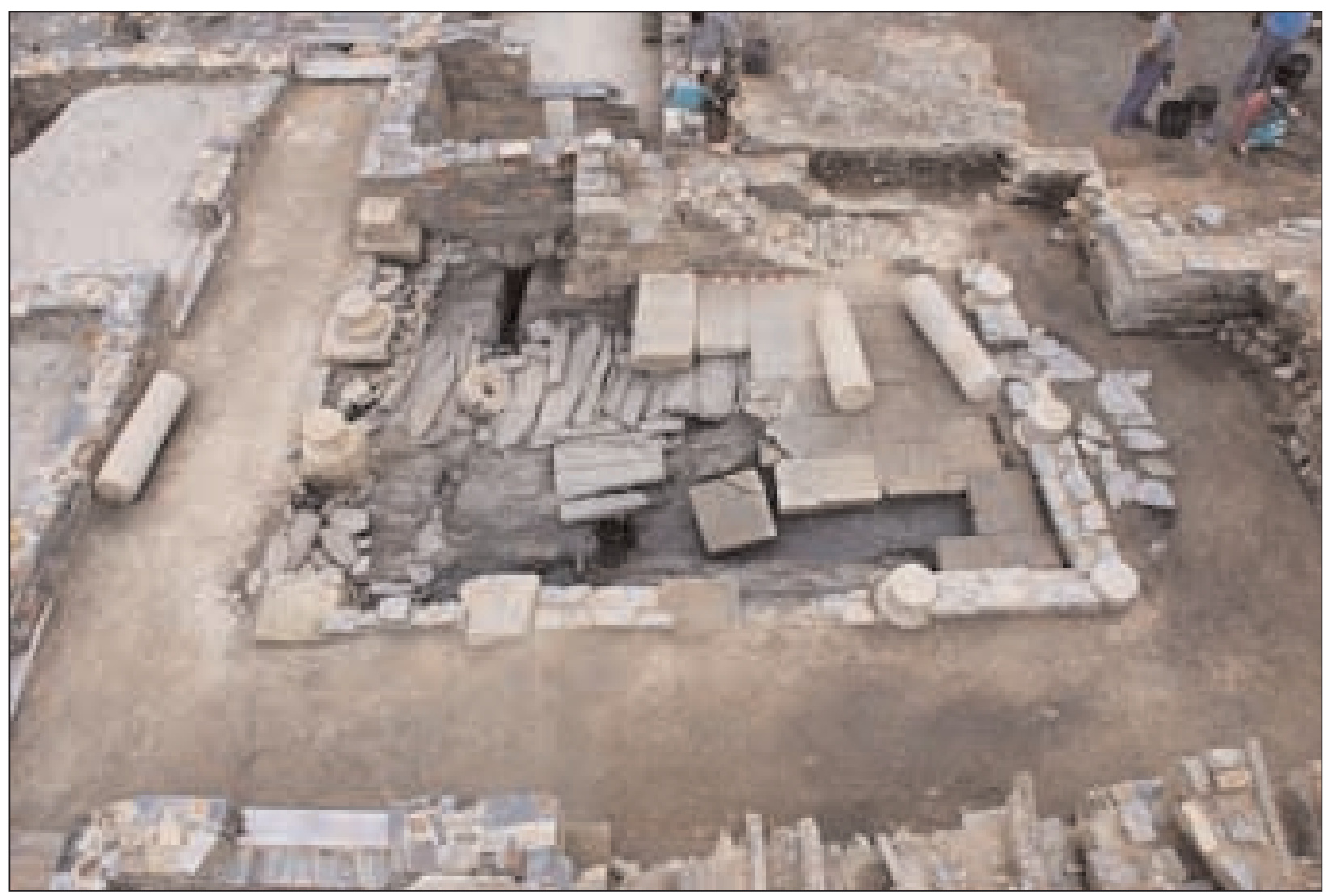

Figura 5: Atrio columnado al cual se abren las principales estancias de la casa y una de las escaleras que daba acceso al piso superior.

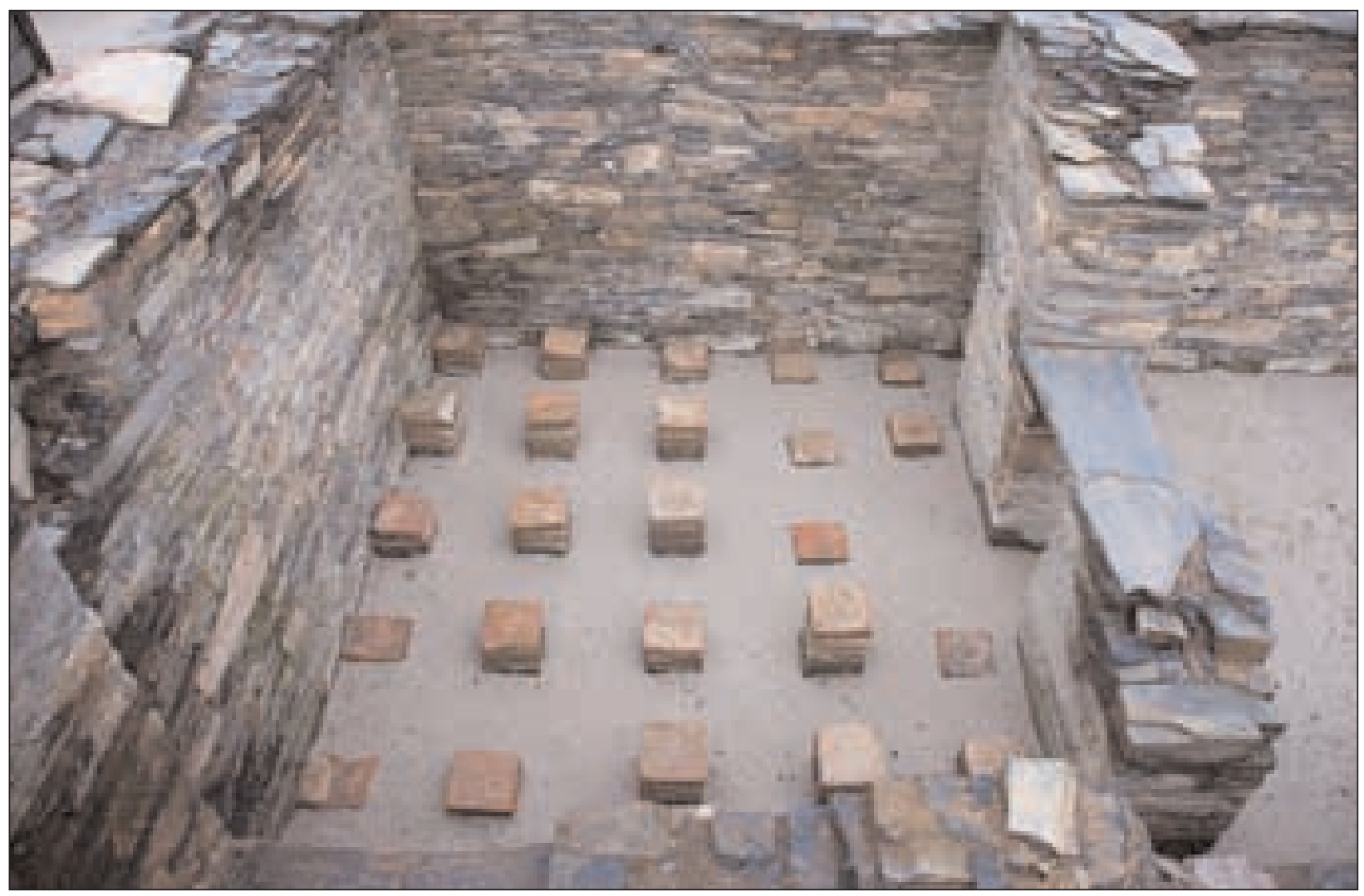

Figura 6: Estancia calefactada en el cuerpo central del edificio en el que la circulación inferior de aire caliente a través del hipocaustum se complementaba con red de tubuli embutidos entre la pared y la carga mural. 


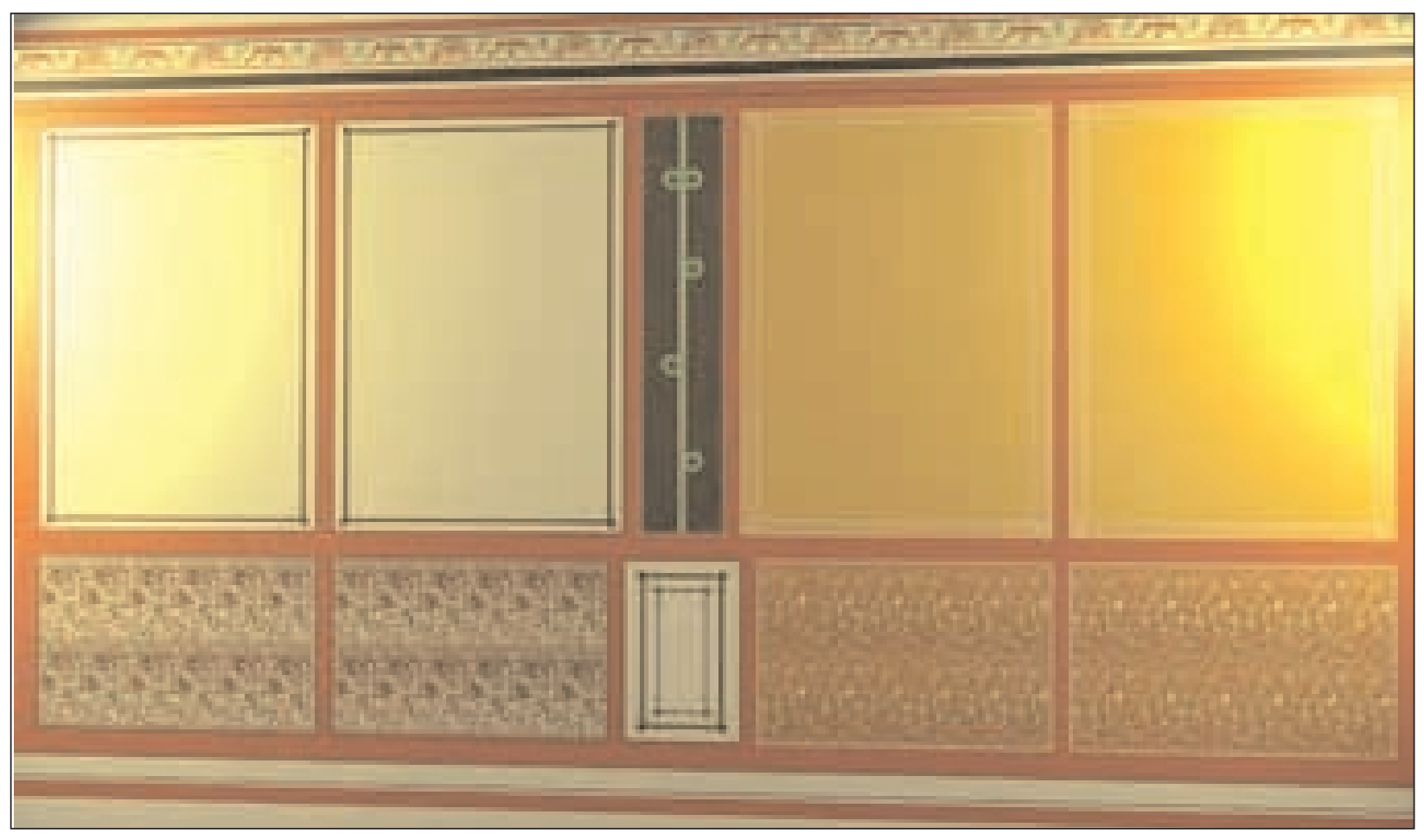

Figura 7: Recreación de uno de los paneles pictóricos de la domus (O. Gago, C. Berlanga, B. Madariaga).

Tras varios episodios de refortificación relacionados con el establecimiento de efectivos militares en el antiguo castro (Villa et alii., 2006) y su probable consolidación como centro administrativo el Chao Samartín adquiere en el siglo II condición de asentamiento abierto en el que las fortificaciones han perdido su centenaria justificación. Un episodio que parece coincidir con el abandono definitivo de la gran casa romana y el sistemático expolio de los elementos arquitectónicos más llamativos (sillares de granito, columnas, etc.) y de aquellos ocasionalmente reaprovechables (ladrillos, tuberías o tegulae). Las antiguas cabañas, de planta sencilla y recinto único, son sustituidas ahora por espacios compartimentados interiormente mediante tabiques de piedra o agrupadas para formar núcleos familiares más amplios. Muchas de estas viviendas dispusieron de dos alturas, pavimentos de hormigón y cargas murales decoradas con pinturas policromas.

En definitiva, un nuevo contexto para el viejo asentamiento que requirió de espacios aptos para la celebración de los actos públicos y ceremonias consustanciales con su función administra-

3 Frente al edificio, custodiados en un pequeño edículo se conservaron algunos de los instrumentos de uso probable en las liturgias oficiales: un juego de 15 pesas en bronce y un tiva. Éste se dispuso tras la puerta y dominando la vía que franqueaba el acceso al poblado. Allí se abría, a modo de plaza, un amplio recinto íntegramente pavimentado y dotado de bancos corridos sobre los muros norte y oeste (fig. 08). Un espacio concebido para la representación social a modo de reinterpretación rústica de los fora convencionales que, no en vano, se construyó sobre los restos de la gran cabaña comunal de la Edad del Hierro y adosado a la escalinata que debió servir de acceso monumental a la sauna castreña, entonces ya profundamente reformada. Se trata, por tanto de un espacio cargado de simbolismo en el que, aunque reinterpretado en clave romana, perdura buena parte de su significación ideológica anterior ${ }^{3}$. De hecho, este conjunto ceremonial se repite, conjugando los mismos elementos y reproduciendo con idénticas dimensiones el edifico principal, en el castro de Coaña. Al igual que en el Chao Samartín, la vía de acceso supera la puerta interior del poblado, flanqueada también allí por sendos cuerpos de guardia, para alcanzar la plataforma rectangular que a modo de tribuna, ligeramente sobreeleva-

excepcional ejemplo de hasta, fabricado en hierro, de enmangue tubular y unos 0,71 m de hoja (VILLA, 2009: 220 y 242). 


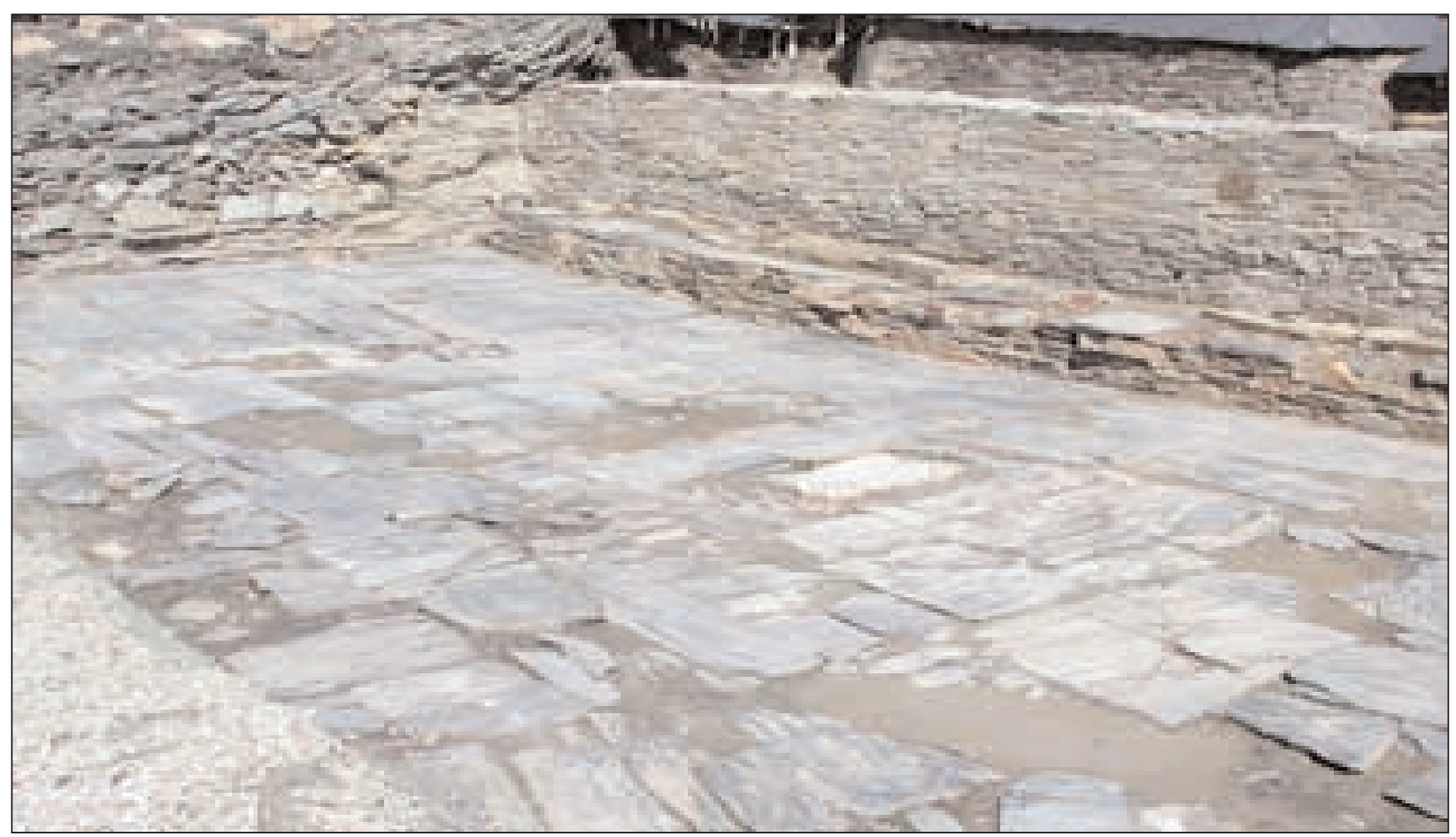

Figura 8: Espacio pavimentado con bancos corridos que se abre hacia la puerta del poblado. Compone, junto con la sauna castreña y otros elementos arquitectónicos un espacio de uso comunitario presente en otros castros como Coaña. Por su analogía simbólica y funcional podrían considerarse una especie de foro castreño, adaptación rústica de sus referentes urbanos.

da respecto a la calzada se levanto frente al recinto ocupado por las primitivas saunas castreñas. Esta plataforma, interpretada tradicionalmente como torreón, no es más que la solución arquitectónica que permitió configurar, de acuerdo a un patrón perfectamente establecido, el escenario indispensable para la representación y el ejercicio ritual del poder (fig. 09).

La prosperidad que caracterizó la vida de los habitantes de la población romana se vio bruscamente interrumpida durante la segunda mitad del siglo II d.C., cuando una sacudida sísmica de gran intensidad provocó la ruina del poblado y su definitivo abandono.

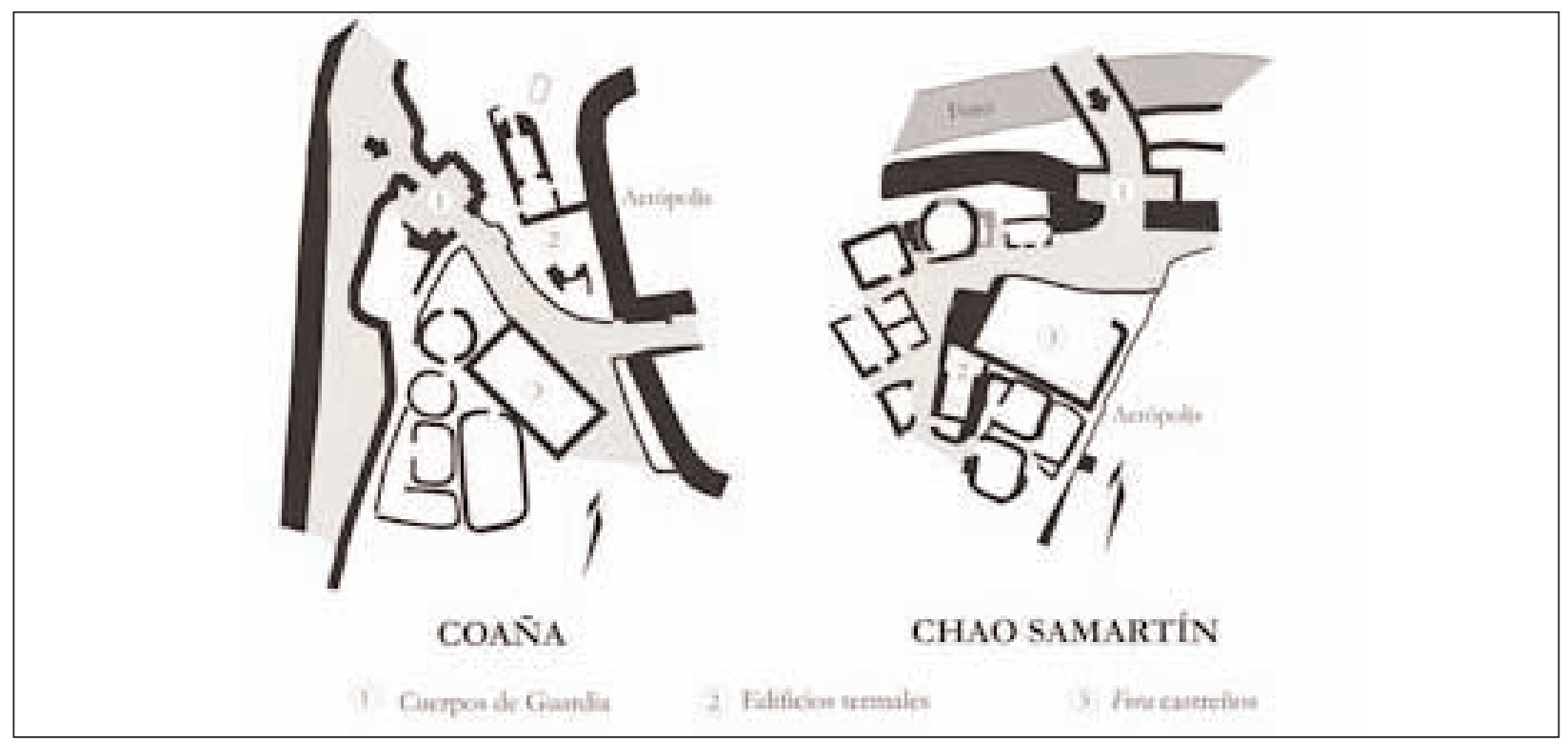

Figura 9: Croquis en el que se advierte cierta fidelidad a un patrón común en el planteamiento escenográfico de los "fora castreños" del Chao Samartín y Coaña. 
Tras un largo hiato sin ocupación ni uso alguno del lugar, a partir del siglo VIII d.C., coincidiendo con los albores de la monarquía asturiana, se constata el expolio sistemático de las ruinas del poblado castreño y posterior desarrollo de un espacio funerario en torno a las ruinas de la domus. Aunque se registran enterramientos hasta fines de la Edad Media la necrópolis conoce su máxima expansión durante los siglos IX-X d.C. (Villa et alii., 2008).

\section{FORMACIÓN Y PERVIVENCIA DEL DEPÓSITO ARQUEOLÓGICO}

Para comprender las circunstancias que hicieron posible la creación y pervivencia de un depósito arqueológico como el conservado en el Chao Samartín es indispensable considerar acontecimientos de naturaleza y antigüedad muy diversa, algunos de los cuales se remontan a tiempos prehistóricos, que se repitieron felizmente en siglos posteriores y que tienen, en todo caso, como última justificación la singular consideración que el lugar alcanzó entre las comunidades que habitaron este territorio durante más de dos milenios.

La relevancia del lugar fue notable ya desde época prehistórica. La voluntad manifiesta de monumentalización que animó el establecimiento de la Acrópolis durante el Bronce Final acentuó el protagonismo paisajístico de un paraje que conciliaba su insólita accesibilidad, si nos atenemos al patrón del que participan el resto de asentamientos fortificados conocidos en la región, con una posición topográfica muy relevante, de perfiles abruptos y aparente dificultad, para componer una escenografía de indiscutible eficacia si de lo que se trataba era de captar la atención incluso a gran distancia.

Poco sabemos de las formas sociales que propiciaron su afianzamiento como referente territorial, pero lo cierto es que su preeminencia sobre las comunidades vecinas perduró aún tras los cambios que condujeron, al inicio de la Edad del Hierro, a la ruina el primitivo establecimiento, para mantenerse todavía vigente hacia el cambio de Era, cuando se consuma la conquista y plena implantación romana en Asturias.

Será esta condición de referente territorial la que propicie que, en el marco de la organización imperial, se institucionalice la condición del viejo asentamiento castreño como centro administrativo y residencia principal. Una posición de privilegio que incentivó entre los habitantes del pobla- do la demanda de productos y servicios suntuarios en un proceso de emulación y alarde que el establecimiento de efectivos militares favoreció definitivamente. La presencia de tropas significó en este contexto, amén de la garantía de un aprovisionamiento más o menos regular de productos suntuarios, la incorporación en el tejido social indígena de un poderoso catalizador que habría de acelerar el proceso de asimilación cultural y desintegración de la sociedad castreña tradicional. Su estacionamiento en la zona se prolongó hasta finales de la primera centuria, décadas en las que se promovió la consolidación de élites locales como principales agentes de la administración imperial entre la población indígena.

Es probable que lo ocurrido en el Chao Samartín encontrase correspondencia en otras comarcas vecinas donde determinados asentamientos debieron adquirir un rol similar de capitalidad y a los que, por consiguiente, cabe suponer un nivel de prosperidad y ostentación equivalente. Sin embargo, la precipitada destrucción y consiguiente abandono del poblado otorgaron a este yacimiento una condición excepcional que amplifica sustancialmente su relevancia arqueológica.

Tras los efectos devastadores del cataclismo que asoló el poblado en la segunda mitad del siglo II d.C. (Fig. 10), y a pesar del rastreo posterior al que sin duda se entregaron sus habitantes en pos del rescate de pertenencias y posibles víctimas, el repertorio de bienes abandonados por extravío, rotura o imposible traslado han conformado uno de los depósitos arqueológicos más ricos, interesantes e históricamente expresivos de cuantos se conocen en Asturias.

\section{UN ASENTAMIENTO CON ÉXITO}

Un interminable historial de pliegues, fallas y cabalgamientos conforman en el área suroccidental de Asturias un relieve de valles encajados entre montañas de amplios niveles de cumbres y suave topografía que facilitaron, desde el Neolítico, el tránsito entre la costa y las tierras altas interiores. Eran itinerarios con certeza amables para hombres y ganado pues les mantenían alejados de los riesgos inherentes a los ambientes frondosos que saturaban el fondo de valle o que implicaba, cuando se hacía inevitable, el vadeo de los ríos.

El rosario de monumentos tumulares y megalíticos que jalonan estas sierras son testimonio 


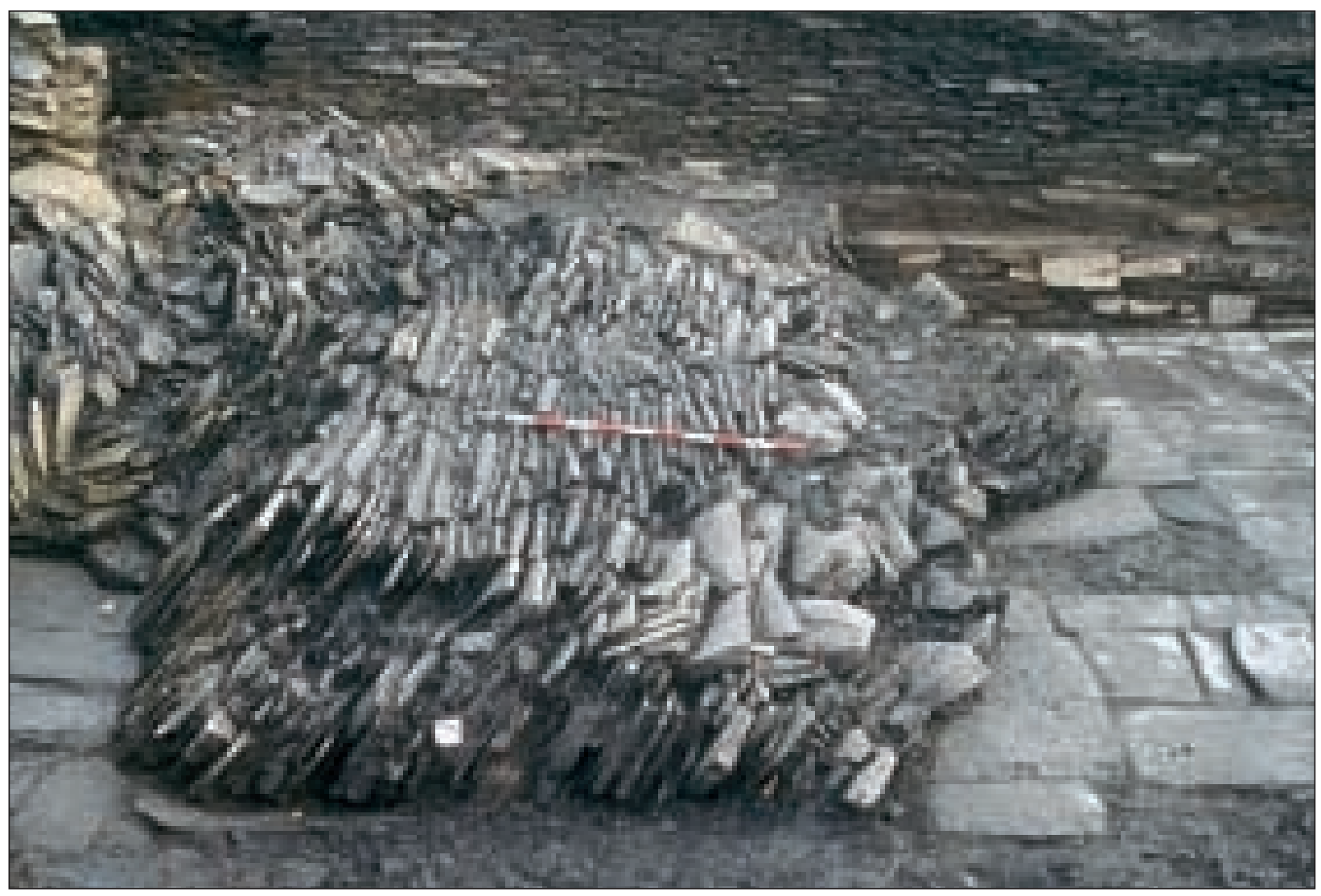

Figura 10: Durante la segunda mitad del siglo II d.C. se constata la ruina violenta y compacta de la mayor parte de edificios del poblado. La imagen muestra una de las paredes de la plaza caída en bloque sobre el pavimento.

fehaciente de la vigencia milenaria de aquellos primitivos caminos. Algunos de ellos convergen en el entorno inmediato al Chao Samartín. Hacia este lugar se abren los pasos serranos para descubrir una orografía que constrasta poderosamente con el paisaje de montaña circundante. Aquí, la penillanura degradada y disecada por la red fluvial actual determina la segmentación topográfica del espacio en extensos llanos de suelos cuaternarios, idóneos para la explotación agropastoril. Al menos desde comienzos del IV milenio estos campos fueron destino de comunidades neolíticas cuyas tumbas se conservan, en número de varias decenas, en torno al que habría de ser asentamiento castreño (Sánchez, 1999; Villa, 2009b).

Sobre los apenas $6 \mathrm{Km}^{2}$ comprendidos entre los lugares de Xestoselo y Robledo se distribuyen los tres principales conjuntos de túmulos Canadeiro, Cereixeira y Zarro das Tumbas- delimitando un área en el que no cabe otro pasillo de tránsito que el constituido por la dorsal de Castro, la misma sobre la que se asienta el Chao Samartín (fig. 11). Se perfila de esta forma la conformación desde tiempos neolíticos de un itinerario cuya trascendencia en el establecimiento de un asentamiento estable en la zona se mostrará con toda rotundidad en los momentos terminales de nuestra Prehistoria Reciente.

Y es que si este territorio desempeñó un papel importante en la articulación de los itinerarios prehistóricos de ámbito comarcal, durante el Bronce Final puede asegurarse que se encontraba plenamente integrado en circuitos de intercambio de más amplio alcance pues Grandas de Salime era estación inevitable en el itinerario que, atravesando la Cordillera Cantábrica, abasteció durante el Bronce Final los territorios de Lugo y Orense de productos cupríferos generados en los ricos criaderos del Nalón (de Blas, 1992: 133). En estas circunstancias, el tratamiento monumental otorgado al cierre de la Acrópolis, precisamente hacia el año 800 a.C., supondría el refrendo paisajístico de una preeminencia social que pudiera derivarse de los beneficios generados por su ventajosa posición como lugar de paso en un circuito comercial que, al igual que en otros muchos puntos de la Europa atlántica de comienzos del I milenio, estimuló el desarrollo de prósperas comunidades en territorios de frontera étnica o cultural (RuizGalvez, 1998: 227). 


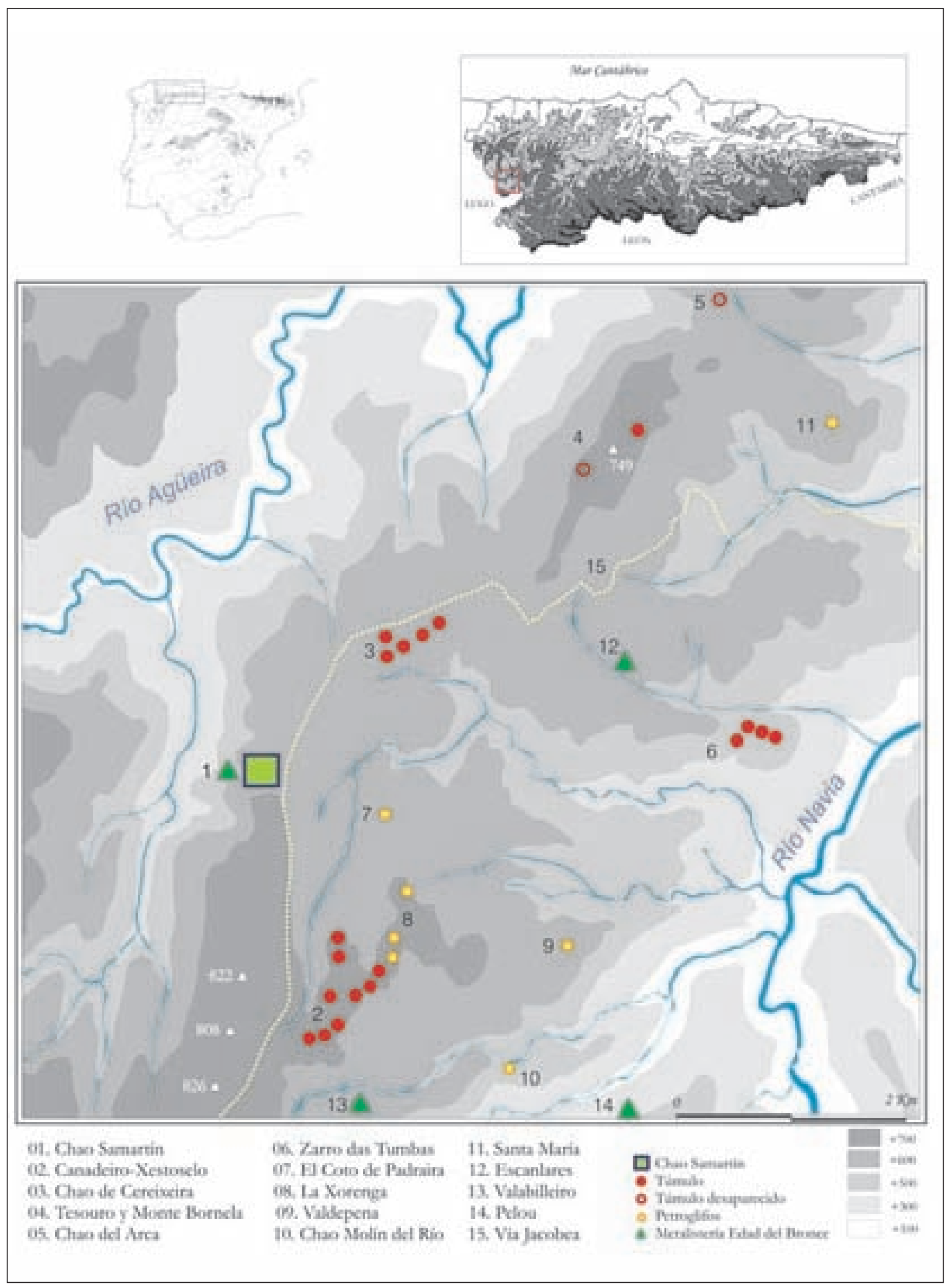

Figura 11: El Chao Samartín se localiza en el curso de diversos itinerarios cuya vigencia se remonta a la Prehistoria reciente. El plano muestra su posición respecto a los principales conjuntos tumulares del entorno. 
Durante la Edad del Hierro el Chao Samartín no perdió su pujanza si esta puede valorarse en función de la monumentalidad del aparato defensivo que se estableció en torno al caserío castreño. Al menos un gran foso y una muralla, varias veces vencida y reformada, magnificaron durante siglos la imagen de esta comunidad. La adopción temprana de soluciones constructivas que afectaron tanto a las fortificaciones como a la trama edificada interior -que luego habrían de generalizarse en el resto de asentamientos castreños- son muestra de la vitalidad, capacidad de renovación y, también, de cierta ascendencia sobre las comunidades de su entorno.

Tras la conquista y la incorporación de los pueblos trasmontanos al Imperio, el modelo de organización territorial establecida por Roma no hizo sino acentuar las diferencias que subrayan la singularidad del Chao Samartín frente a otros asentamientos vecinos.

Tal y como se ha descrito en trabajos anteriores, la implantación romana en esta región parece haber tomado como referencia determinados poblados preexistentes que, por una u otra razón, reunían condiciones para desempeñar un papel destacado en la organización administrativa y política del territorio. De esta forma, algunos castros asumieron, bajo control imperial, un rol de centralidad respecto a las comunidades del entorno que probablemente refrendaba administrativamente una posición secular de prestigio y ascendencia. Así, al igual que ocurrió entre los pueblos luggones con la Campa Torres (Maya et alii. 2001: 261), entre los pésicos con San Chuis (Villa, 2007c: 177) o con El Castelón de Coaña entre los albiones (Villa, 2007d: 44), sucedió con el Chao Samartín entre los pueblos lucenses del interior.

En este caso, otras circunstancias, también poderosas, impulsaron la adaptación del viejo núcleo castreño al nuevo orden establecido bajo dominio romano. Localizado sobre el itinerario que comunicaba las capitales de ástures trasmontanos y galaicos lucenses -Lucus Asturum y Lucus Augusti- la importancia del Chao Samartín

${ }^{4}$ La implantación de efectivos militares se produce tanto en poblados de la Edad del Hierro, remozados durante el siglo I, caso del Monte Castrelo de Pelóu, como en asentamientos de nueva fundación con morfología y planteamientos poliorcéticos plenamente romanos como el denominado castro de San Isidro, en cuyo dispositivo defensivo están ausentes los rasgos que habían caracterizado las fortificaciones locales de se vio realzada por la necesidad estatal de organizar la explotación de un territorio rico en depósitos auríferos cuyo beneficio resultaba, tras la reforma monetaria de Augusto, de extraordinaria importancia para la buena marcha de las finanzas imperiales. Se conjugaron así dos condicionantes decisivos que habrían de caracterizar implantación romana inicial sobre el antiguo castro y el territorio colindante: la necesidad de un control policial efectivo y la capacidad técnica suficiente para la identificación y puesta en marcha de las explotaciones mineras. En estas circunstancias la participación del ejército resultó inexcusable en su condición de instrumento idóneo para dirigir y tutelar la organización del trabajo, establecer las cargas tributarias asumibles por cada comunidad -entre las que es probable se contase también el trabajo en las minas (Orejas, 2005: 314)- y garantizar su percepción. De esta forma el Chao Samartín adquirió durante las décadas centrales del siglo I d.C. el perfil marcadamente militar que denuncia su registro arqueológico, común a otros asentamientos de la comarca ${ }^{4}, y$ que habría de perdurar hasta el final de la centuria (Villa \& Gil, 2006; Villa et al. 2006) (Fig. 12/13).

\section{EL CHAO SAMARTÍN EN ÉPOCA ROMANA}

Mientras la hipótesis de la fundación romana de los castros, y su aparente respaldo arqueológico, gozó de credibilidad fue posible eludir una cuestión que ahora se presenta como capital: la caracterización de las comunidades que habitaron los castros durante la Edad del Hierro y sobre cuyo sustrato cultural habría de conformarse una nueva sociedad que, en apenas unas décadas, haría ostentación de su romanidad. En la actualidad, aunque resulte paradójico, la constatada antigüedad del fenómeno castreño y consiguiente ruina del modelo de colonización imperial que preconizaba la fundación generalizada de poblados fortificados tras la conquista, lejos de menoscabar la importancia del influjo romano, realza el vigor y eficacia del impulso romanizador entre las comunidades indígenas. Y es que la romanización

la Edad del Hierro para levantar un perímetro amurallado continuo, de tendencia poligonal y remate de ángulos en esquina de naipe, o la introducción de otros elementos exóticos como las piedras hincadas, instaladas a modo de cervi y cippi sobre agger, recursos en su conjunto propias de la poliorcética romana (Villa, 2007). 


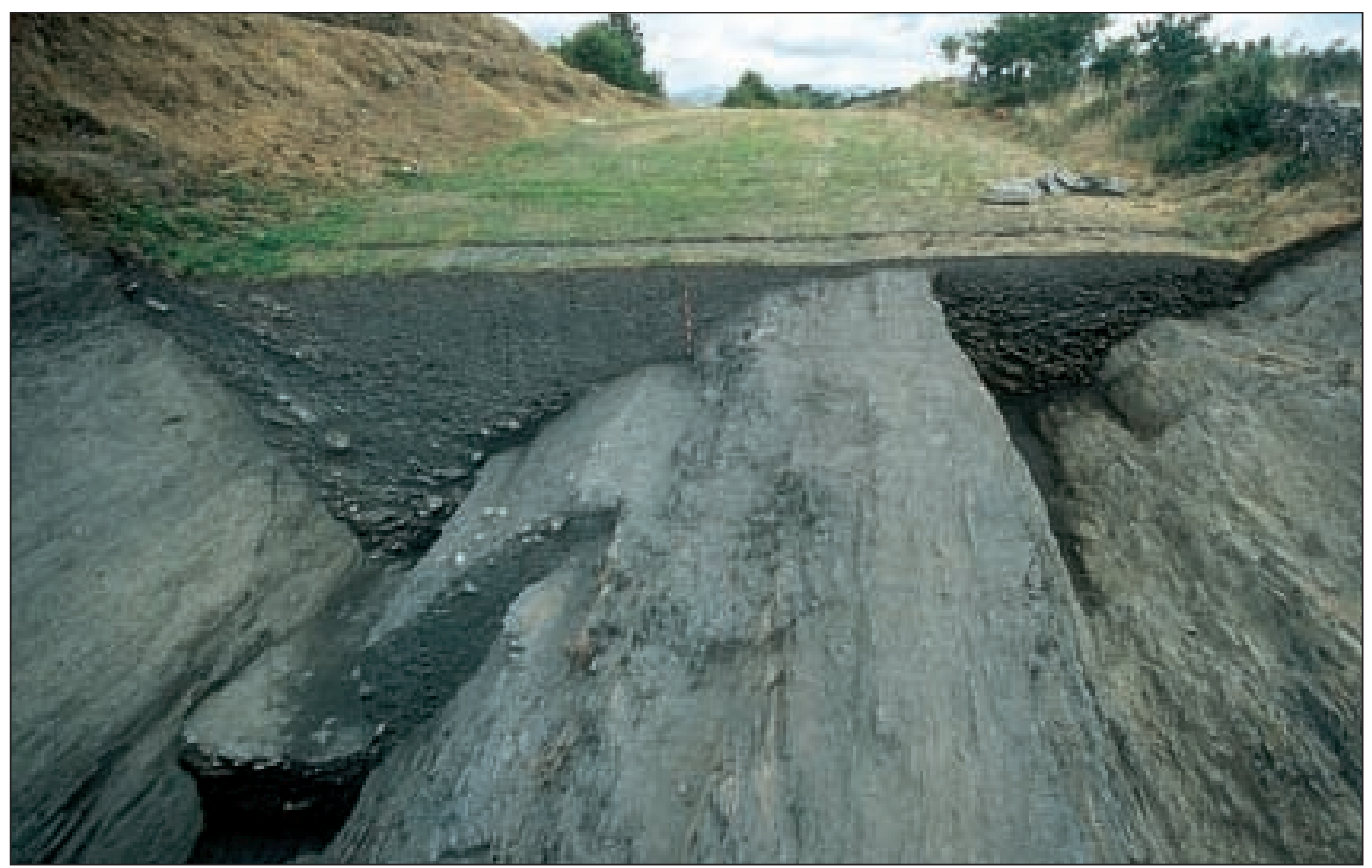

Figura 12: Los fosos exteriores muestran una larga secuencia de uso y reforma que culminaría hacia finales del siglo II con el paulatino relleno de las trincheras. Se muestra la sección original del gran foso así como el perfil de su posterior reexcavación para conformar el doble foso definitivo.

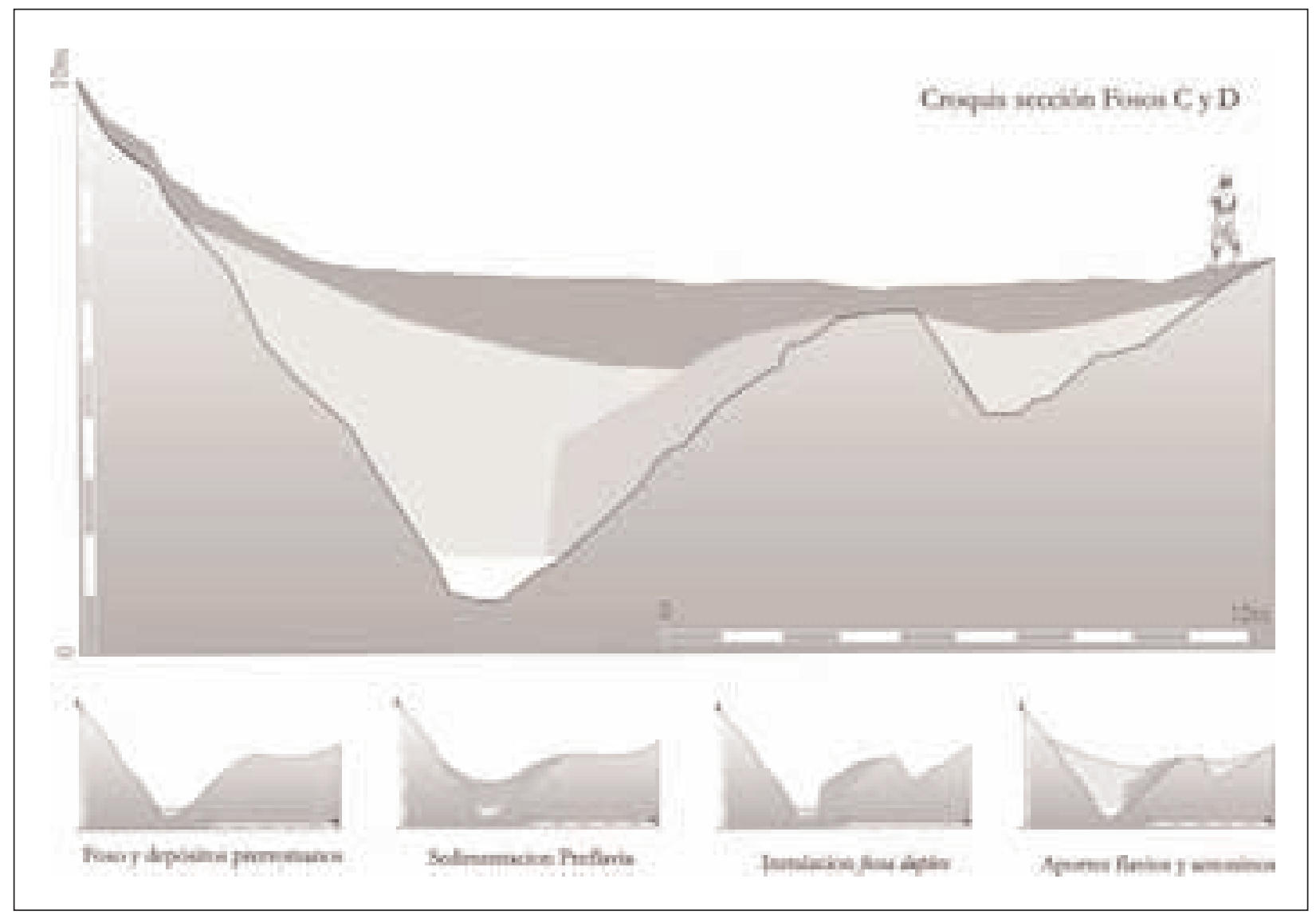

Figura 13: Croquis en el que se muestra la secuencia cronoestratigráfica de los fosos exteriores. 
adquiere en estos territorios unos rasgos singulares que la distancian formalmente de lo acontecido en otras zonas peninsulares ${ }^{5}$, pero no más o en la misma medida, que divergían los atributos de las sociedades prerromanas sobre las que actuaron. Incluso, desde esta perspectiva, la realidad arqueológica podría justificar la defensa de una transformación tanto o más eficaz de los grupos prerromanos norteños frente a otros de romanización, si se quiere, más convencional. La adopción del uso epigráfico, la monetarización de los intercambios o la sustitución generalizada de los ajuares cerámicos constituyen acontecimientos relevantes sólo comprensibles si se contemplan como prueba de la integración e inequívoca aceptación de los valores propios del mundo romano.

Frente a la carencia de indicios reseñables de implantación urbana en la Asturias de época altoimperial, los castros se muestran aún hoy como el hábitat hegemónico de la región durante los siglos I y II d.C. El aire arcaico de su arquitectura así como la penuria endémica en el repertorio de productos genuinamente romanos proyectaron sobre este territorio, con el poderoso aval de la literatura clásica, la imagen de un espacio primitivo, tercamente refractario al influjo de la cultura romana. Un paisaje en el que la débil permeabilidad a las nuevas ideas se vislumbraba en aspectos tan específicos como la introducción ocasional de nuevos patrones constructivos o la relativa concentración de materiales importados en castros singulares como la Campa Torres o el propio Chao Samartín. Evidencias que, en todo caso, refrendaban una romanización epidérmica, modesta y desigual, protagonizada por grupos de población muy restringidos al frente de una masa social ajena a los usos y costumbres del invasor.

La lectura que hoy se afianza de aquella sociedad surgida tras la conquista en la Asturias de los siglos I y II de la Era es, sin embargo, muy diferente $^{6}$. No se trata ya de especular con estadios de romanización establecidos por ratio de terra sigillata o numerario, sino que se impone la evidencia de un territorio férreamente controlado a partir de una presencia militar relativamente modes-

5 Sobre el "topos" historiográfico de la romanización: Fernández Ochoa y Morillo, 2002

6 Un cambio generado por la renovación metodológica de la investigación que se desarrolla desde mediados de los años

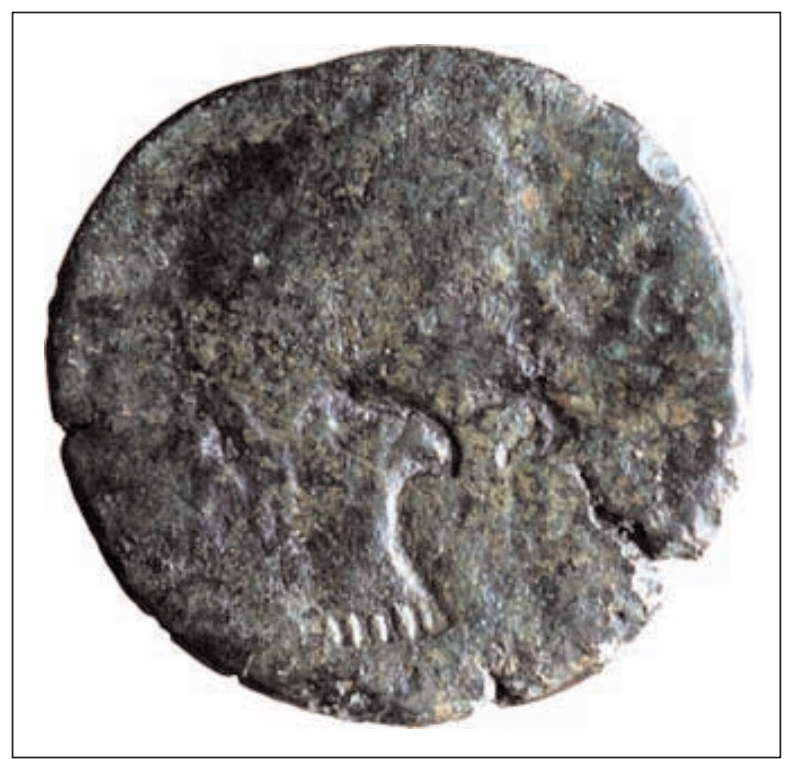

Figura 14: El ambiente militarizado que predominó durante el siglo I d.C. encuentra abundantes testimonios en el Chao Samartín y otros castros de la comarca (importaciones cerámicas, armamento, numerario). En la imagen moneda contramarcada con figura de águila.

ta, pero suficiente (fig. 14), y el ascenso a categorías aristocráticas de grupos locales socialmente destacados cuyos vínculos tradicionales de relación con la comunidad se instrumentalizarán al servicio del interés imperial.

La unidad administrativa básica de esta organización fue la civitas, figura jurídica que se sirvió de lugares con secular tradición de centralidad, caso del Chao Samartín, para brindar el escenario adecuado al ejercicio del poder en sus vertientes judicial, fiscal y militar. Tal elección recayó aquí en un núcleo en el que convergían además otras funciones, ejercidas probablemente desde tiempo ancestral, que permiten considerar, a partir de los testimonios epigráficos recuperados en el yacimiento, su identificación con alguna de las entidades de población mencionadas en las fuentes de la época (Fig. 15).

Ya se ha hecho mención a la posición favorable del Chao Samartín respecto a itinerarios transitados desde la Prehistoria que hubiese podido propiciar su consolidación como mansio, vicus viarii o, considerar verosímil su identificación con alguno de los fora que se desarrollaron en el

noventa en el marco de programas de larga duración y ámbito comarcal, como el Proyecto Gijón o el Plan Arqueológico del Navia-Eo, del que los trabajos que aquí se presentan son tributarios. 


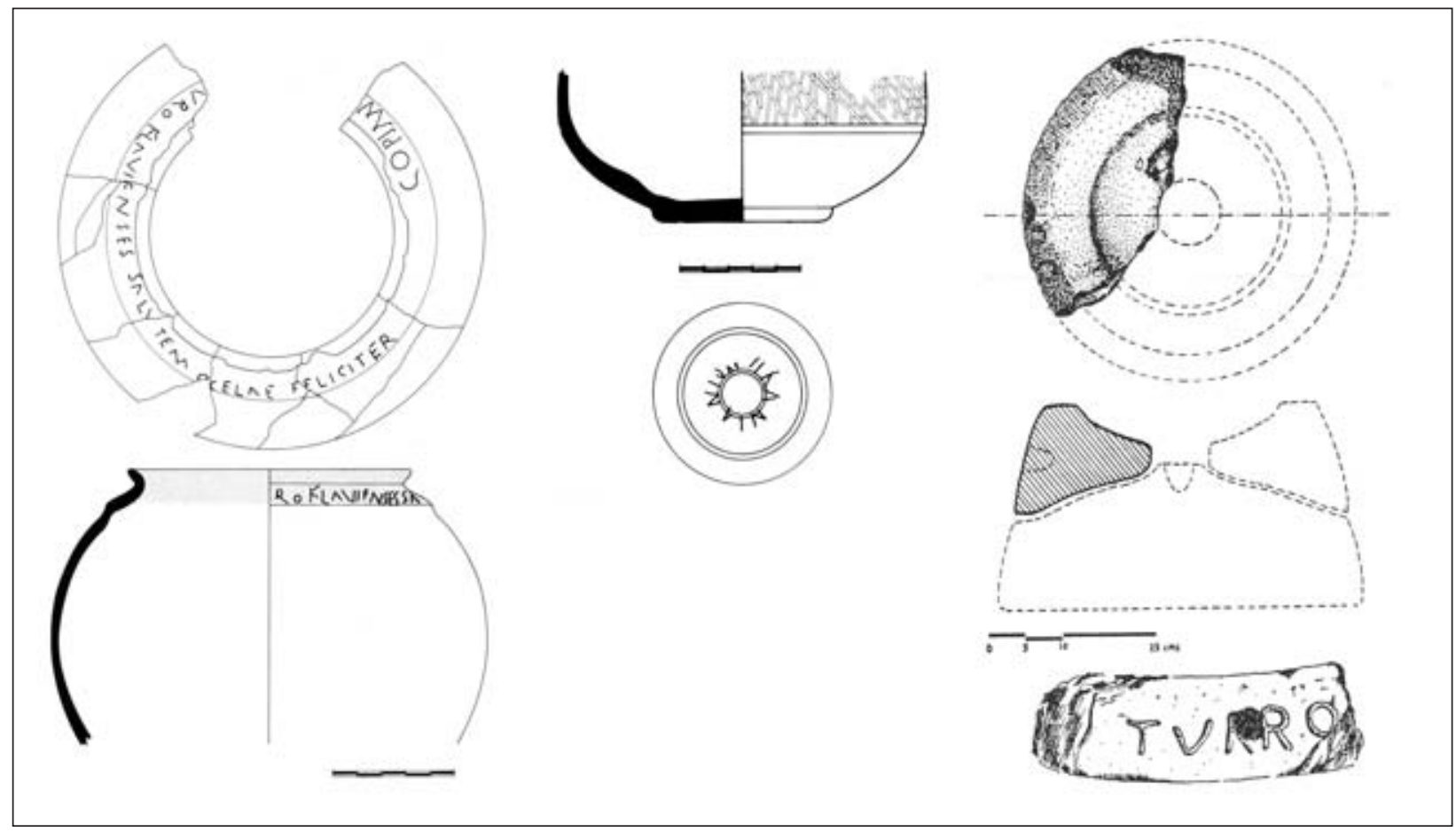

Figura 15: Inscripción sobre cerámica en la que se hace referencia a los lugares de (B)vroflavia y Ocela (¿Chao Samartín?) y otros epígrafes que pudieran relacionarse con la toponimia local en época romana, Elanianivm, recuperado en el Chao Samartín y Tvrro, procedente del castro de San Chuis (según A. García Linares).

noroeste peninsular a fines del siglo I d.C. como centros urbanos de vocación preferentemente comercial (Arias, 1992: 64). La configuración de la trama urbana con edificios singulares particularmente aptos para este fin y la aparición de juegos de pesas serían coherentes con tal afirmación (Naveiro, 1991: 173).

La orientación administrativa que el poblado adquirió durante el periodo de tutela militar que caracterizó el ambiente castreño durante el siglo I d.C. no es incompatible, además, con otros atributos de carácter ideológico perfilados ya desde su ocupación prehistórica. Desde la instalación del complejo ritual de la Acrópolis -no se olvide, ordenado en torno a una gran piedra- hasta su conversión en espacio funerario durante el Altomedievo, todo apunta la relevancia del asentamiento en el ideario de los habitantes del entorno para los que parajes de esta naturaleza conservarían, durante siglos, la condición de hito litúrgico cuyo significado se proyectaba, más allá de lo religioso, sobre actos jurídicos y protocolarios ${ }^{7}$.

7 Baste recordar el texto que encabeza la inscripción datada en el siglo VIII procedente de Carrio, un pequeño núcleo rural del concejo de Villayón, ribereño también del río Navia: $I(n)$ petra a q(ua) dieri-bus em(e)re cepi nonia qu(e)
Así pues, del mismo modo que se ha sugerido para la ciudad de Lugo (Arias \& Villa, 2005: 3000), en la ratificación por parte de la autoridad romana de la prevalencia ancestral del Chao Samartín podría reconocerse su condición de centro ritual o conciliabulum.

En definitiva, a lo largo del siglo I d.C. se entrevé la agregación en el Chao Samartín de atributos y cometidos que por su condición vertebradora deben interpretarse como rasgos indisociables en la caracterización del antiguo castro prerromano como centro administrativo relevante ¿caput civitatis?- y, como tal, receptor de las cargas fiscales establecidas sobre las comunidades adscritas a su territorium cuyo control se ejercerá desde centros secundarios militarizados como Monte Castrelo de Pelóu, de donde procede una inscripción interpretada como probable tabula censualis, en la que se refieren los individuos o grupos familiares sometidos a contribución en el territorio vinculado al castellum (Villa et al., 2005) (Lám. 16/17). De hecho, la presencia de 
juegos de pesas y medidas en singulae civitates, vienen siendo consideradas instrumento oficial no tanto al servicio de la población como de los recaudadores (Balil, 1984: 181). En este caso, el fraccionamiento y cuidada elaboración de las piezas localizadas en el Chao Samartín sugieren su empleo en el intercambio o valoración de mercancías suntuarias entre las que podría encontrarse el oro producido en las minas de la comarca. La tributación con metal, o en su defecto como mano de obra en el laboreo minero se contaría de esta forma entre las prestaciones o munera de la civi-

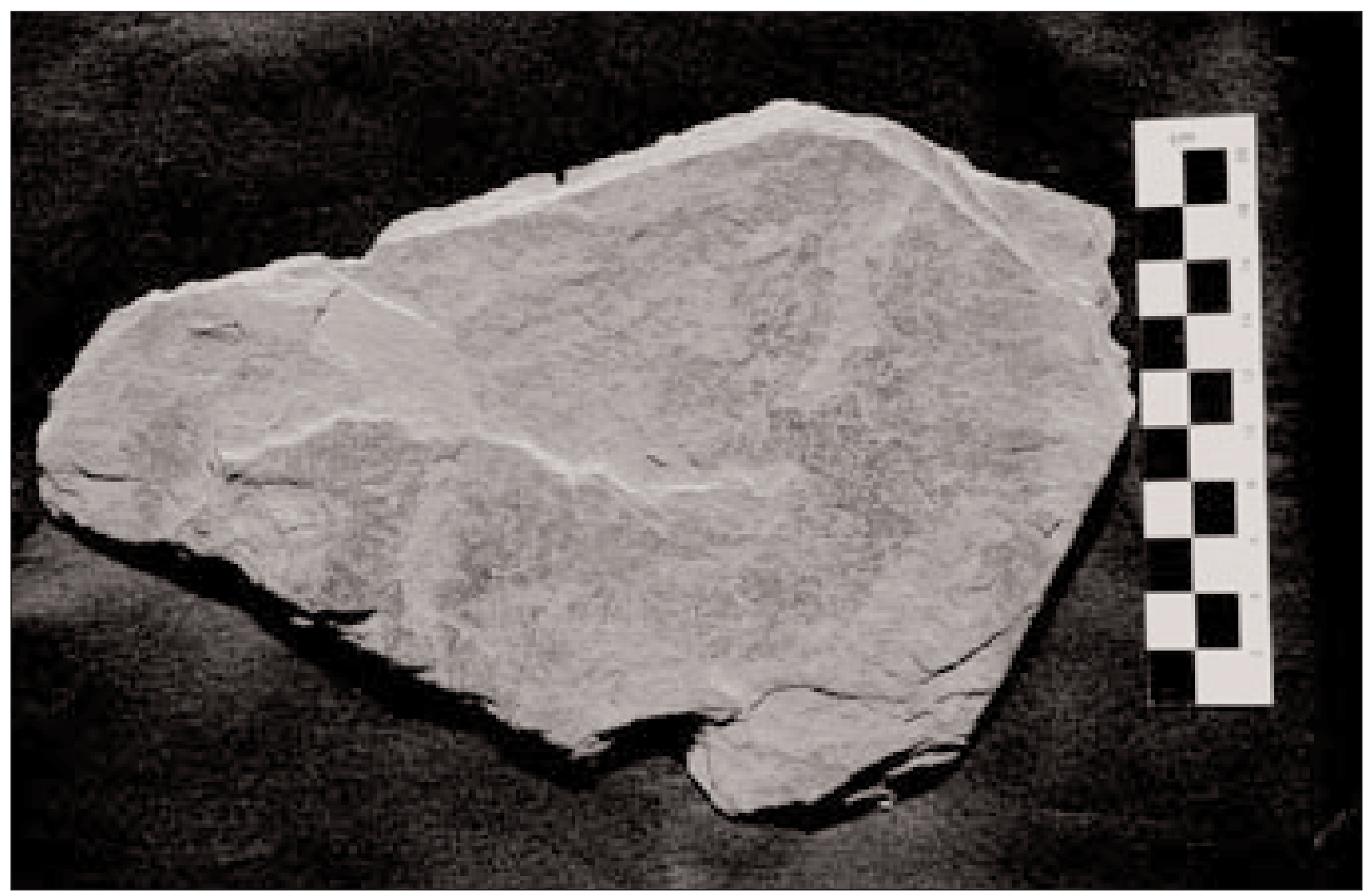

Figura 16: Inscripción en letra cursiva datada en el siglo I d.C. en el que se enumeran varias docenas de individuos en lo que parece constituir un censo o tabula censualis. Procede del Monte Castrelo de Pelóu.

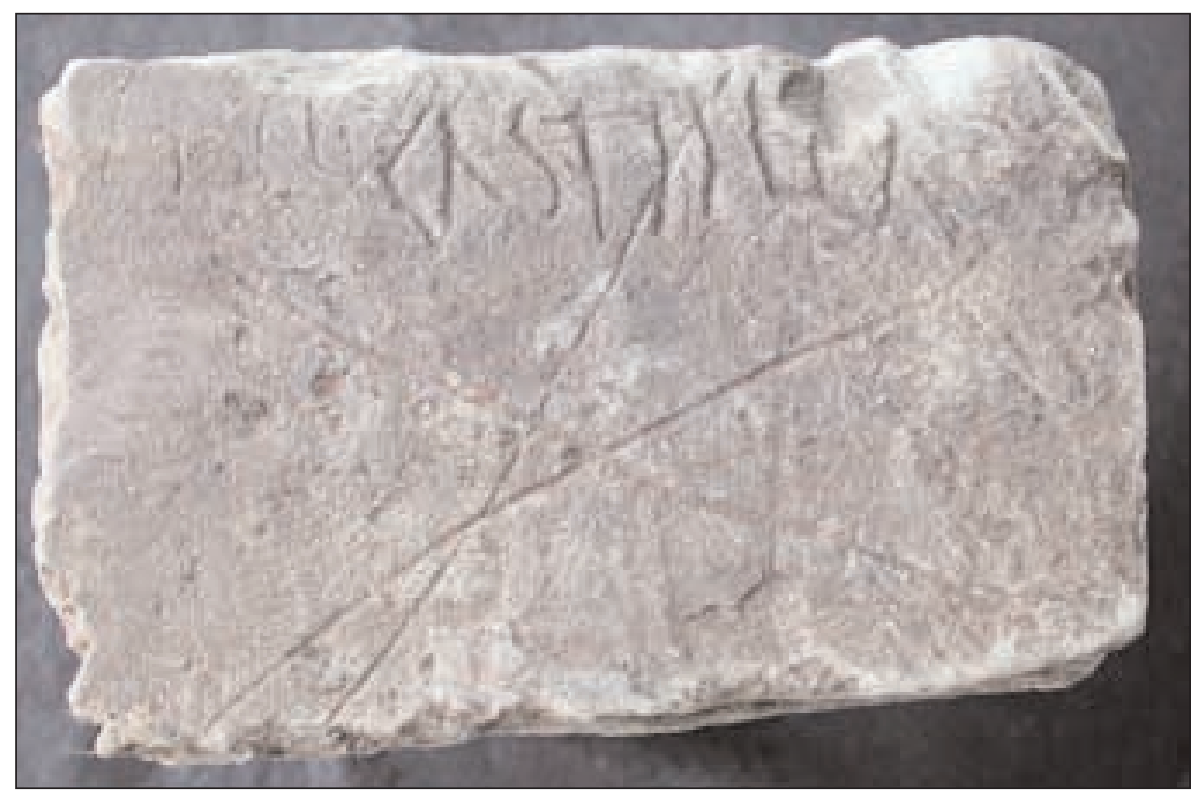

Figura 17: Inscripción sobre sillar de arenisca con el texto CASTEL(O) procedente de Monte Castrelo de Pelou. 
tas sumando a los cometidos del Chao Samartín del siglo I el de officinae metallorum, condición propuesta para establecimientos de rango secundario desde los que se ejercería de forma efectiva el control técnico y supervisión administrativa de las zonas mineras (Sánchez-Palencia et alii. 2007: 144). A favor de tal condición puede argumentarse la presencia abundante de instru- mental y subproductos metalúrgicos empleados en el tratamiento del oro y la plata (herramientas cerámicas de fundición con salpicaduras y goterones metálicos, piedra de toque, etc.) cuya presencia se registra generosamente tanto durante el periodo de tutela militar como durante la segunda centuria en ambientes inequívocamente locales ${ }^{8}$. (Fig. 18/19)

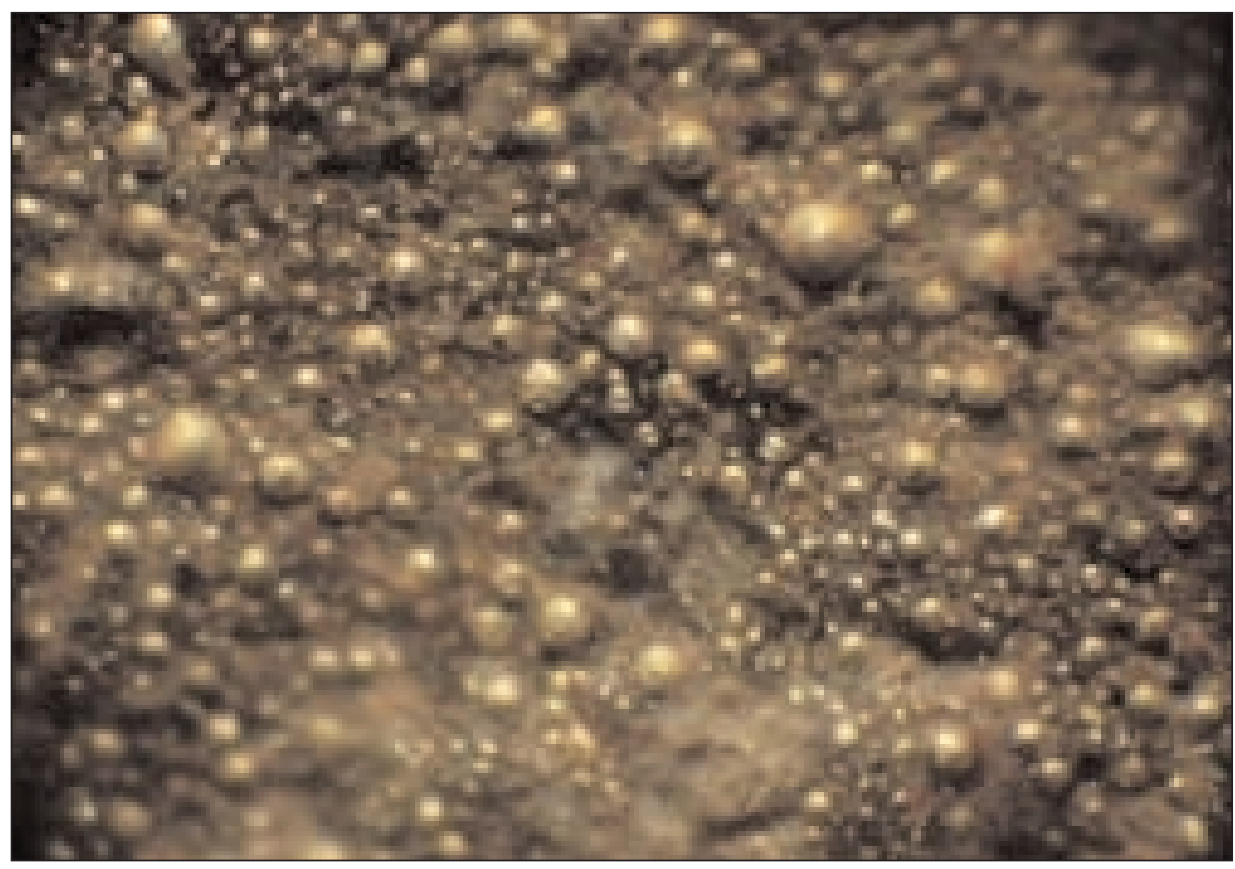

Figura 18: Cerámica común romana con empleo metalúrgico y cuya superficie interna se muestra intensamente perlada con goterones y salpicaduras de oro. Recuperada en ambientes indígenas del siglo II d.C.

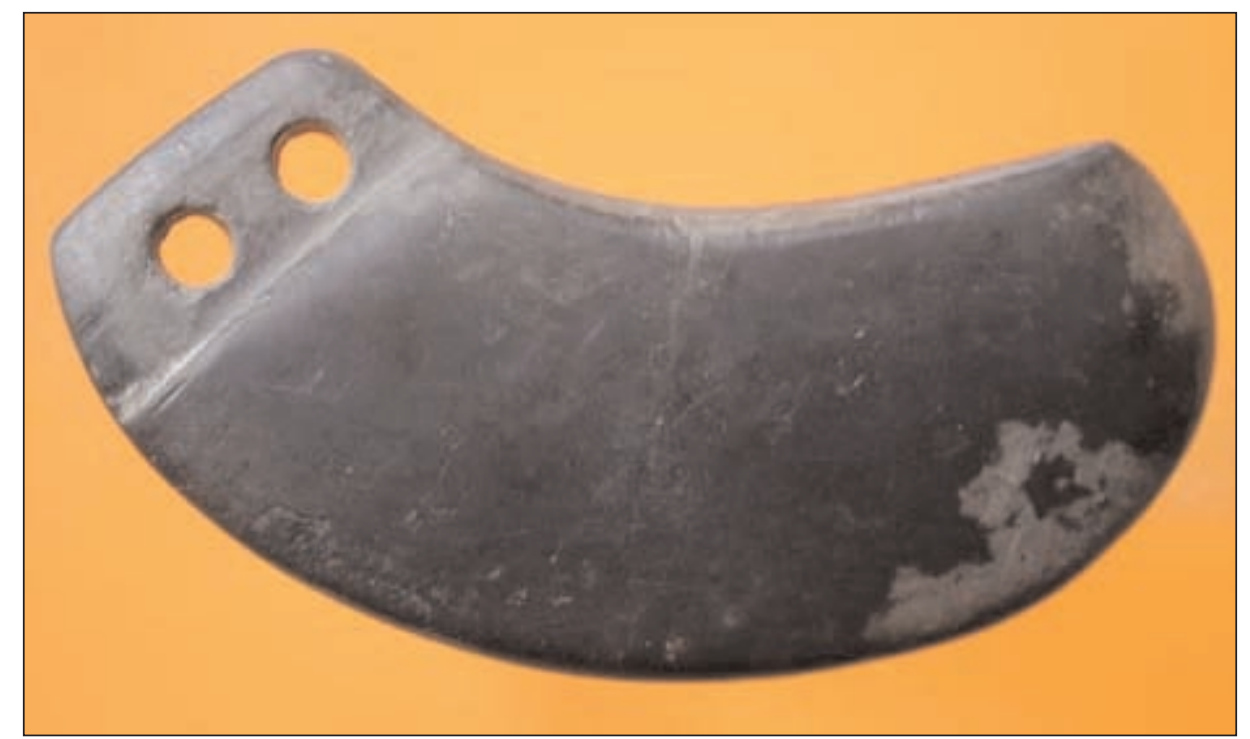

Figura 19: Piedra de toque fabricada en lutita. Procede de ambientes indígenas del siglo II d.C.

${ }^{8}$ La mayor parte de los materiales referidos están integrados en Samartín (Villa, 2009).

la exposición permanente del Museo Castro de Chao 
En definitiva, lo que se propone es que el afianzamiento del Chao Samartín como centro relevante en la nueva organización territorial romana materializó la superposición, física y sociológica, del poder imperial sobre el conglomerado de pactos, creencias y convenciones que articulaban la sociedad indígena. Significó la apropiación del símbolo y de sus atributos convenientemente adaptado a los requerimientos de un gobierno cuyo último objetivo fue la inmediata puesta en explotación del territorio sometido a su influencia. La conversión de este espacio físico en un espacio jurídico y fiscal -la civitas- no resulta- ría en absoluto ajeno a las comunidades afectadas y justificaría de forma razonable el reconocimiento del viejo poblado castreño como cabecera territorial o caput civitatis. Y de semejante voluntad no cabe expresión arqueológica más contundente que la construcción de la domus (Fig. 20/21), símbolo inequívoco de status y sede distinguida para las relaciones sociales (Fernández Vega, 1999: 455), que levantada en el corazón de la comunidad castreña, usurpó un espacio principal dentro del recinto fortificado, del castro, sin duda alguna el icono más poderoso y representativo de la sociedad prerromana del NW peninsular.

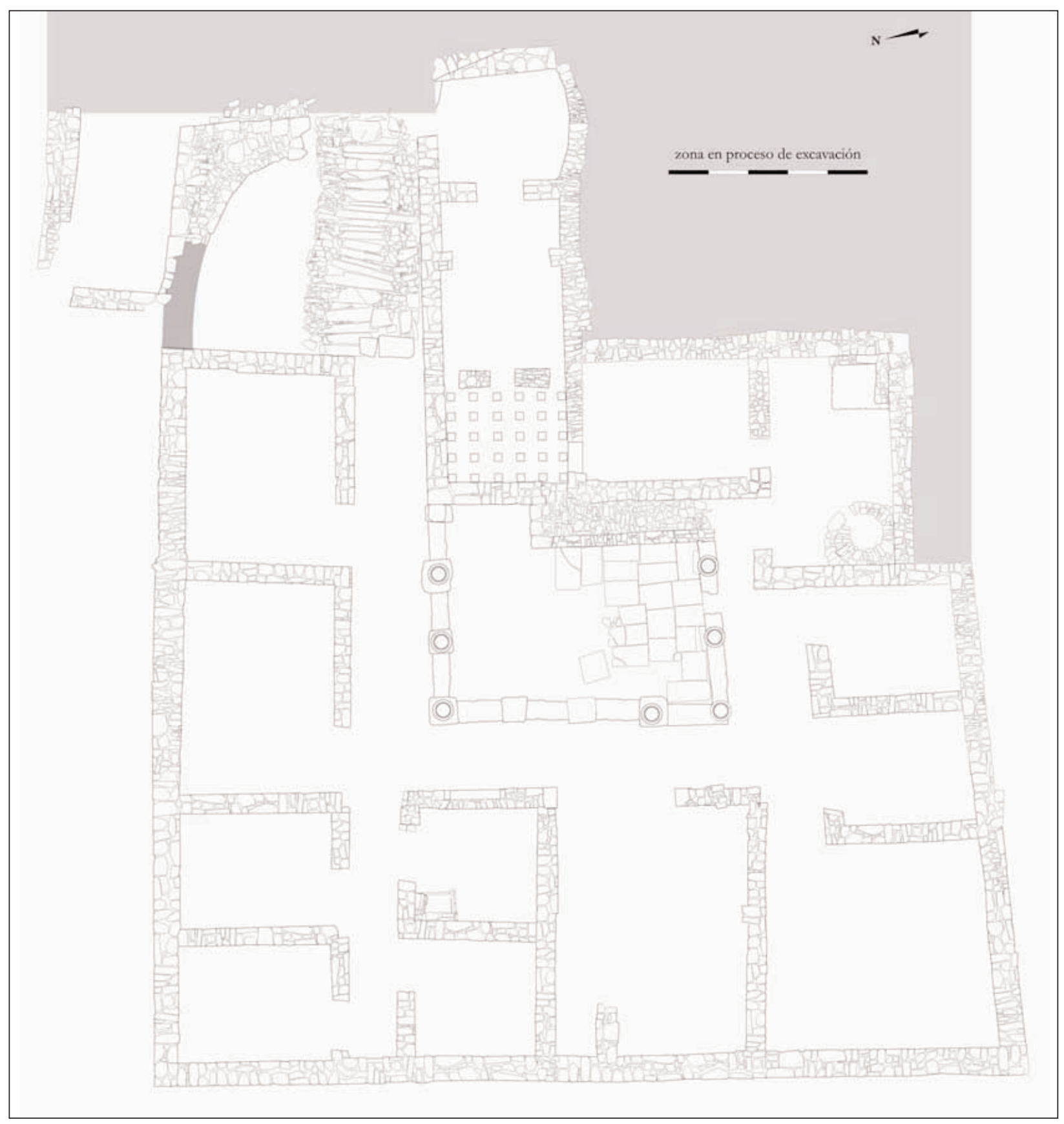

Figura 20: Plano del área excavada de la domus a finales de 2008. (Plano: E. Martín) 


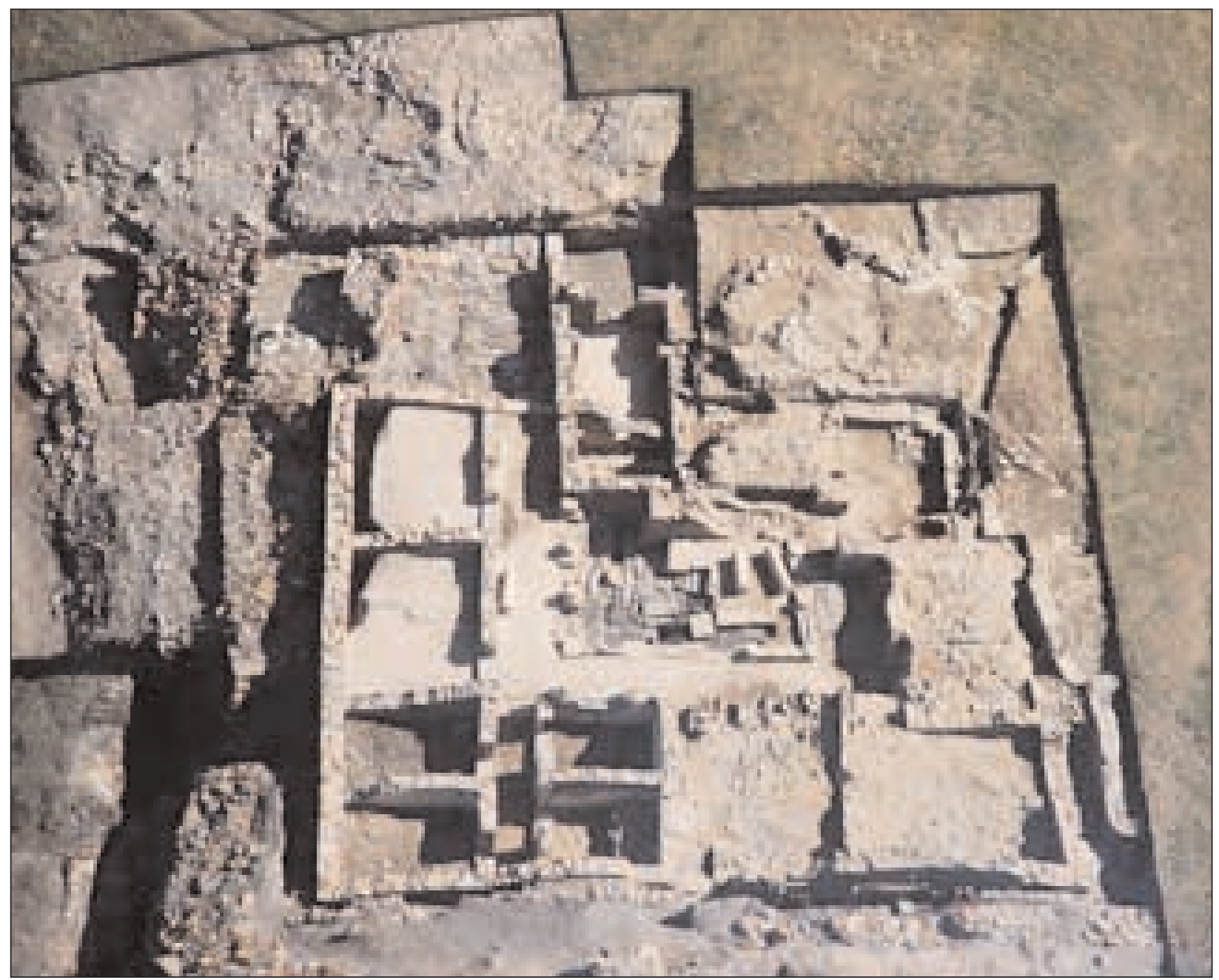

Figura 21: Vista cenital de la domus durante la campaña de excavación de 2008.

\section{BIBLIOGRAFIA}

ARIAS VILAS, F. (1992): A romanización de Galicia. Historia de Galicia 4. Vigo

ARIAS VILAS, F. y VILLA VALDÉS, A. (2005): “El poblamiento romano en el territorio de los galaicos lucenses", en C. Fernández Ochoa y P. García Días (Ed. Cient.): Unidad y diversidad en el Arco Atlántico en época romana. BAR International Series 1371. Oxford, 297-308.

BALIL ILLAN, A. (1984): "El modio de Ponte Puñide (Gonzar, Pino, Coruña), en Gallaecia 7-8. Santiago de Compostela, 179-186.

BLAS, M.A. de (1992): "Nuevos testimonios metalúrgicos de la Edad del Bronce en el centro-occidente de la región cantábrica", en Veleia 1991-1992. Vitoria, 109-137.

DIEGO SANTOS, F. (1993): Inscripciones medievales de Asturias. Asturias.
FERNÁNDEZ OCHOA, C. y MORILLO CERDÁN, A. (2002): "Romanización y asimilación cultural en el Norte Peninsular. Algunas reflexiones sobre un topos historiográfico desde una perspectiva arqueológica", en M.A. de Blas y A. Villa Valdés (Ed.): Los poblados fortificados del noroeste de la Península Ibérica: formación y desarrollo de la Cultura Castreña. Navia, 261-277.

FERNÁNDEZ VEGA, P.A. (1999): La casa romana. Madrid.

GAGO MUÑIZ, O. (2008): "La pintura mural romana en el castro de Chao Samartín", en J. Rodríguez Muñoz (Coor.): La Prehistoria en Asturias. Oviedo, 809-816.

GAGO MUÑIZ, O. (2009): La pintura mural en A. Villa (ed.): Museo Castro Chao Samartín. Grandas de Salime. Asturias. Catálogo. Oviedo, 214-217.

GONZÁLEZ Y FERNÁNDEZ-VALLES, J.M. (1976): Miscelánea histórica asturiana. Oviedo. 
MADARIAGA, B.; BENEÍTEZ, C.; VILLA, A. (2001): "Material latericio en el Castro de Chao Samartín (Grandas de Salime)"; en C. Fernández Ochoa y V. Entero (Ed.): II Coloquio Internacional sobre temas romanos en el occidente del Imperio. Gijón, 389-396

MAYA, J.L. y CUESTA, F. (2001): "Excavaciones arqueológicas y estudio de los materiales de $\mathrm{La}$ Campa Torres", en J.L. Maya y F. Cuesta (Ed.): El Castro de la Campa Torres. Período prerromano. Serie Patrimonio 6. Ayuntamiento de Gijón, vtp editorial, pp. 11-277.

MARCOS, A. y RUIZ, F. (1978): San Martín de Oscos. Mapa Geológico de España E. 1:50.000. Instituto Geológico y Minero de España. Ministerio de Industria. Madrid.

NAVEIRO LÓPEZ, J.L. (1991): El comercio antiguo en el N.W. peninsular. Monografías urxentes do museo arqueolóxico 5 . A Coruña.

OREJAS SACO DEL VALLE, A. (2005): “El poblamiento romano en los distritos mineros del noroeste", en C. Fernández Ochoa y P. García Días (Ed. Cient.): Unidad y diversidad en el Arco Atlántico en época romana. BAR International Series 1371. Oxford, 309-319.

RUIZ-GÁLVEZ PRIEGO, M. (1998): La Europa atlántica en la Edad del Bronce. Un viaje a las raíces de la Europa occidental. Madrid

SÁNCHEZ HIDALGO, E. (1999): "Excavación arqueológica del Túmulo I del conjunto tumular de $\mathrm{La}$ Xorenga (Xestoselo, Grandas de Salime)", en Excavaciones arqueológicas en Asturias 19951998, 233-236. Oviedo.

SÁNCHEZ-PALENCIA, F.J.; FERNÁNDEZ-POSSE, M.D.; OREJAS, A.; SASTRE, I. y RUIZ DEL ÁRBOL, M. (2007): "Minería romana de oro del noroeste de Hispania", en A. Morillo (Ed.): El ejército romano en Hispania. Guía Arqueológica. León, 135-158.

VILLA VALDÉS, A. (2004): "Orfebrería y testimonios metalúrgicos en el castro de Chao Samartín, Asturias (España)" en A. Perea, I. Montero y O. García (eds): Tecnología del oro antiguo: Europa y América. Anejos de Archivo Español de Arqueología. Consejo Superior de

(2007): "El Chao Samartín (Grandas de Salime) y el paisaje fortificado en la Asturias Protohistórica", en P. Moret y L. Berrocal (Coord.): Paisajes fortificados en la Protohistoria de la Península Ibérica. Madrid, 191-212. (2007b): "Saunas castreñas en poblados fortificados de Asturias y Galicia", en A. Coelho (Coord.): Pedra Formosa. Vila Nova de Famaliçao, 66-92.

(2007c): "El Pico San Chuis: reseña de un yacimiento pioneron en la investigación castreña en Asturias", en Sautuola XII. Santander, 167-179.

(2007d): "Mil años de poblados fortificados en Asturias (siglos IX a.C.-II d.C.)", en J. A. Fernández-Tresguerres (Coord.): Astures y romanos: nuevas perspectivas. Oviedo, 27-60.

(2009): A. Villa Valdés (Ed.): Museo Castro de Chao Samartín. Catálogo. Consejería de Cultura y Turismo del Principado de Asturias y Asociación de Amigos del Parque Histórico del Navia. Oviedo.

(2009b): “A propósito del fenómeno tumular neolítico en Grandas de Salime: la datación carbono 14 del túmulo 1 del Chao de Cereixeira”, en Excavaciones Arqueológicas en Asturias 6, 2003-2006. Oviedo, 309-312

VILLA, A.; FRANCISCO, J. de; ALFÖLDY, G. (2005): "Noticia del hallazgo de un epígrafe altoimperial en el lugar de Pelou, Grandas de Salime", en Archivo Español de Arqueología 78, 191-192, Madrid, 271274.

VILLA VALDÉS, A.; GIL SENDINO, F. (2006): "Aproximación al modelo de implantación de Roma en Asturias", en M.P. GARCÍA-BELLIDO (Coord.): Los campamentos romanos en Hispania (27 a.C.-192 d.C.). El abastecimiento de moneda. Anejos de Gladius 9, Vol. II, 2006. Consejo Superior de Investigaciones Científicas. Madrid, 493-500.

VILLA VALDÉS, A. y CABO PÉREZ, L. (2003): "Depósito funerario y recinto fortificado de la Edad del Bronce en el castro del Chao Samartín: argumentos para su datación", Trabajos de Prehistoria 60-2, Madrid: 143-151.

VILLA, A.; MENÉNDEZ, A. y GIL, F. (2006):"Fortificaciones romanas en el castro de Chao Samartín (Grandas de Salime, Asturias)", en Á. Morillo (coord.): Actas del II Coloquio de Arqueología Militar Romana en Hispania. Producción y abastecimiento en el ámbito militar. Universidad de León, 581-599.

VILLA VALDÉS, A.; MONTE LÓPEZ, R.; HEVIA GONZÁLEZ, S.; V. PASSALACQUA, N.V., WILSON, A.C. y CABO PÉREZ, L. (2008): “Avance sobre el estudio de la necrópolis medieval del Chao Samartín en Castro (Grandas de Salime, Asturias)", en Territorio, sociedad y poder: revista de estudios medievales 3. Oviedo, 57-84. 
